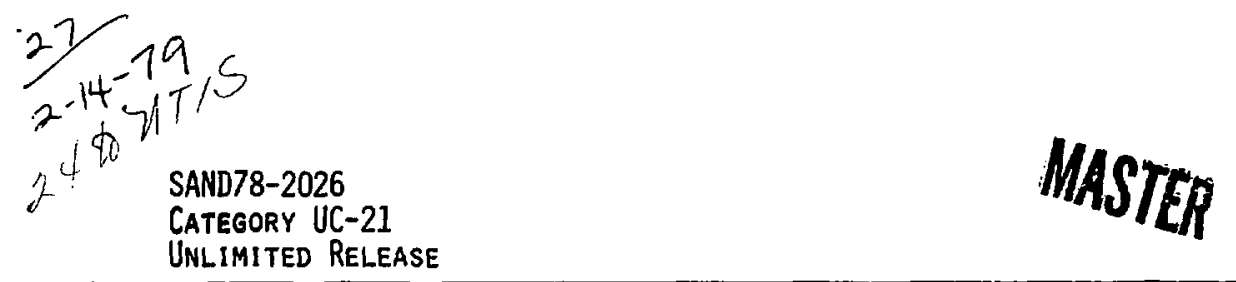

\title{
RELATIVISTIC ELECTRON BEAM ENERGY DEPOSITION \\ IN THIN GOLD AND ALUMINUM TARGETS
}

\author{
E. J. T, Burns, S, A, Goldstein, J, A. Halble ib, \\ L. P. MIX, J. N. OLSEN, J, W. POUKEY, \\ J. P. Quintenz and M. M. Widner
}


TABLE OF CONTENTS

PAGE

Abstract . . . . . . . . . . . . . . . . . . . . . 1

Introduction . . . . . . . . . . . . . . . . . . . . 2

Theoretical ......................... . . . 4 4

Experimental ........................ . . . . 7

Hydra Experiment . . . . . . . . . . . . . . . . . . 19

Experimental Results .................... 19

Theoretical Results ................... 31

Proto I . . . . . . . . . . . . . . . . . 36

Experimental Results ................ 36

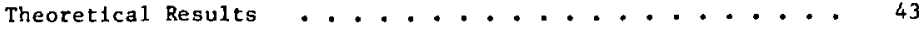

Conclusion . . . . . . . . . . . . . . . . . . . 4 46

References............................. 48

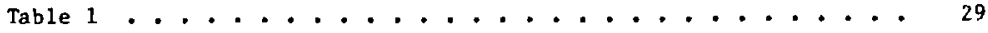

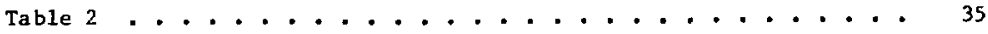

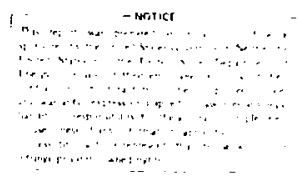


FIGURE NO.

1

2

3

4

5

$\epsilon$

7

Total diode current and Inductively corrected diode

PAGE voltage for (a) Hydra experiments, and (b) Proto-I experiments ......................

Hydra dlode and experimental chamber ...........

Proto-I diode and experimental chamber ........

Spectral and total efficlency response of PIN detector behind 150 micron thick Uranium, 250 mieron thick erbium, 50 micron thick copper, and 300 micron aluminum filters.. Cathode response of aluminum $X R D$ and response as a function of blackbody temperature, where ... . . . . . Temperature, density, and photon escape functions vs. distance into a $25 \mu \mathrm{m}$ thick gold with a $1 \mathrm{TW} / g \mathrm{~m}$ deposition rate utflizing the radiation-hydrodynamic code CHART D. Current density and total current vs. radius for $0.32 \mathrm{~cm}$ carbon $50,25,12.7$, and $6.4 \mu \mathrm{m}$ thick gold on the Hydra experiments ....................... Total current in the diode and effective current in the plnch for single pass electrons vs. t1me for $50,25,12.7$, and $6.4 \mu \mathrm{m}$ thick gold on the Hydra experiments. . . . . Temporal history of the hard $x-r a y$ flux, optical streak apectrum, XUV and optical temperature, and theoretical CHART D prediction for $6 \mu \mathrm{m}$ thick gold on the Hydra accelerator....................... Temporal history of the XUV radiation temperature compared with theoretica1 CHART D predictions for 50,25 , and $12.7 \mu \mathrm{m}$ thick gold folls on the Hydra accelerator. . . . Temporal history of the XUV radiation diagnosics for 8-30 eV (bare XRD), 30-73 eV (0.75 micron Al), and 73-284 ev $\left(0.33\right.$ micron $\left.\mathrm{C}_{8} \mathrm{H}_{8}\right)$ for $6 \mu \mathrm{m}$ gold folls on the Hydra accelerator ................... Time resolved optical spectra observed on the tlydra experiments for the gold folls between 245 and $315 \mathrm{~nm}$. . Theoretical. prediction of forward bremstrahlung as a function of anode escape radius for the $2 \pi$ lsotropic source calculations listed in Table $I$, for comparison with $x$-ray pinhole measurements on the Hydra experiments. . . . . Current density vs. radius for $50,12.7$ and $6.4 \mu \mathrm{m}$ thick gold on the Proto-I accelerator from absolutely calibrated $x$-ray film on the Image plane of a Urantum pinhole camera. Current density and total current vs. radius for 206,89 , 38 , and $6.4 \mu \mathrm{m}$ thick aluminum on the Proto-I accelerator. Current density and total current vs. radius for $6.4 \mu \mathrm{m}$ thick aluminum with $0.5 \mathrm{~cm}$ radius. . . . . . . . . . Temporal history of the radiation temperature measurements on the Proto-I experiments for $25,12.7$ and $6.34 \mu \mathrm{m}$ thick gold folls based on the bare XRD, XUV measurements. Temporal history of the radiation temperature measurements on the Proto-I experiments for 38 and $6.4 \mu$ m thick aluminum based on bare XRD, XUVV neasirements. ..... 
RELATIVISTIC ELECTRON BEAM ENERGY DEPOSITION IN THIN GOLD AND ALUMINUM TARGETS

by

E. J. T. Burns, Steren A. Goldste1n, J. A. halblelb, Sr., L. P. Mix, J. N. Olsen, J. W. Poukey, J. P. Quintenz, and M. M. W1dner Sendia Laboratories, Albuquerque, New Mexico 87185

\section{ABSTRACT}

Relatisistic electron beam (REB) energy deposition in thin gold and aluminum tr.igets has been investigated experimentally using radiation temperature measurements in the soft $x$-ray, vacuum ultraviolet (XUV) and optical spectral regions on two different particle accelerators. Energy deposition measurements were compared with numerical calculations utilizing particle-in-cell (PIC) dlode codes, condensed history Monte-Carlo codes, and coupled radiation-hydrodynamic codes. The specific power deposited (1.e., power deposited/unit mass) was observed to be greater than that due to an average electron making a single pass through a thin target (6.4 $\mu \mathrm{m}$ thick gold foil on the Hydra accelerator and 38 and $6 \mu \mathrm{m}$ thick aluminum folls on the Proto I accelerator). Self-magnetic fleld effects were primarily responsible for deposition enhancement in $6.4 \mu \mathrm{m}$ gold folls on the Hydra accelerator $(\nu / \gamma \simeq 2.5)$. Reduction of electron scattering with aluminum folls on Proto I where $\nu / \gamma \simeq 1$ led to deposition enhancement due to both self electric and magnetic fields. 


\section{INTRODUCTION}

Interest in electron deposition by relativistic electron beams (REB) centers on possible enhancement of collisional deposition resulting from particle dynamics in strong self beam and/or diode electric and magnetic fields. The increase in deposited power per unit mass is due to an increased electron path length in a given amount of material and possibly modification of the stopping power by collective plasma phenomena. Previous papers have studied magnetic stopping or magnetic beam stagnation, ${ }^{1-7}$ electrostatic reflexing, ${ }^{8-10}$ and plasma instabilities, 11,12 In target and anode material.

Enhancement over classical cillisional deposition by a factor of $2.3 \mathrm{hng}$ been reported for $40 \mu \mathrm{m}$ thick aluminum foll by measuring the target expansion velocity on a $450 \mathrm{kV}, 165 \mathrm{kA}, 80 \mathrm{~ns}$ pulse width accelerator. 2 Similarly, deposition enhancement by a factor of 10 has been reported for $10 \mu \mathrm{m}$ thick gold foll in front of $30 \mu \mathrm{m}$ thick polyethylene foil on a $500 \mathrm{kV}, 120 \mathrm{kA}, 30 \mathrm{rs}$ pulse width accelerator, and for $5 \mu \mathrm{m}$ thick gold foll in front of $15 \mu \mathrm{m}$ thick polyethylene foll on a $1 \mathrm{MV}, 330 \mathrm{kA}, 80 \mathrm{~ns}$ pulse width accelerator by measuring the target expansion velocity. 5 Enhancement of specific power deposition (power deposited per unit mass) by a factor of 5 has been observed for $10 \mu$ m thick nickel spherical shells mounted on a stalk by measuring the line integral of the electron density as a function of radius and time from the center of the target utilizing holographic Interferometry. 3 Deposition enhancement factors of 100 have been claimed for aluminum, lead, and polyethylene folls by measuring the temperature, Ion velocity and neutron yleld of the expanding plasma on a $500 \mathrm{kV}, 80 \mathrm{kA}, 80 \mathrm{~ns}$ pulse width accelerator. 12 The role of prepulse (1.e., $10^{-7}$ sec or greater duration, low current, low voltage pulae;) 
prior to the large main pulse (tens of nanosecond duration current and voltage) was known to play a dominant role in the results of the last case. Recently, 10 to $100 \mathrm{mg} / \mathrm{cm}^{2}$ thick carbon, aluminum, titanium, tantalum, and gold folls were found to have no enhancement by measuring the radiation temperature with soft $x$-ray, vacuun ultraviolet (XVV) radiation detectors, at current densities of $0.4-1.0 \mathrm{MA} / \mathrm{cm}^{2} .13$ In this last experiment, detailed theoretical modeling of the experiment was not available, and in particular, hydrodynamic fofl expansion was negiected.

In this paper we present detafled theoretical and experimental results of electron number density, current density, temperature, and specific power for experiments wth a variety of unbacked thtn aluminum and gold foils. We also show that radionetric measurements in confunction with detalled simulations, yield reliable energy deposition data.

The theoretical computational models include Monte Carlo codes, single particle diode codes, and a coupled radiation-hydrodynamic code. The Monta Carlo codes include effects of (a) collisions only, (b) collisions with non self-consistent magnetic flelds in different versions. The Monte Carlo code was useful for studying magnetically enhanced deposition, as well as the effects of scattering, in targets of arbitrary thickness. The diode code can predict deposition in the 1imlt of negligible beam target interaction or with a simplified scattering and energy loss model. This model was useful for computing deposition in very thin folls in realistic dlode geometries. Energy deposition in the folls was determined by comparing experimentally measured temperatures with radiation temperatures predicted by the coupled radiation-hydrodynamic code CHART D. 14 
In addition to the usual voltage and current monttors, diagnostics Include the following: (1) quantitative $x$-ray pinhole photography; (2) apertured, absolutely calibrated, PIN diodes to measure the absolute $x$-ray flux; (3) calibrated optical photodiodes and vacuum photo-electric diodes (1.e., $x$-ray diodes or XRDs) to measure the thermal radiant flux and equivalent blackbody temperature; (4) time resolved opt1cal spectra to verify the continum emission during the power pulse and also to view the late time, low density plasma; and (5) time integrated XUV measurements to discern any line emission in this spectral region. Under appropriate assumptions, the current density as a function of radius and time, as well as the total current in the pinch was deduced from the hard $x$-ray deta.

\section{THEORET ICAL}

The use of simulations codes to model the steady state behavior of REB diodes has been well documented. $15,16,17,18$ These codes employ a particle-in-cell (PIC) technique to calculate the electron and fon behavior In their self-consistent electric and magnetic flelds. Gross diode behavior (such as total electron and Ion current, plnch profiles, and typical particle trajectories) can be obtained with such a diode if the beam target Interaction is negligible. Diode codes have been used to study diodes in which the beam target interaction was not negligible in the case of an assumed anode plasma of fintte thickness. ${ }^{3,19}$ In order to study enhanced deposition in thin folls, a simple macroscopic mode 1 of small angle scatter and stopping power was added to the usual diode code. $^{20}$

The scatering model is valid for small angles of deflection. Rather then samping from a distribution of scattering angleg, as done in a Monte 
Carlo model, an average scattering is computed ustag the formula

$$
\left\langle\theta^{2}\right\rangle=\ell / \gamma^{2} \beta^{4} z
$$

where $\gamma=\left(1-\beta^{2}\right)^{-1 / 2}, \beta 18 \mathrm{v} / \mathrm{c}, \mathrm{v}$ is the velocity of the electron, $\mathcal{L}$ is the distance an electron travels in the material. ${ }^{21}$ Here $L$ is a characterigtic length of the material,

$$
L^{-1}=4 \pi n_{1} z^{2} r_{0}^{2} n_{1} \Lambda
$$

$\Lambda$ ls the ratto of maximum to minimum scattering angel ( $1 \mathrm{n} \Lambda=10$ is used In these 6imulations), $r_{0}$ is the classical electron radius, $n_{1}$ is the foil Ion density, and $z$ is the atomic number of the foll material. The small angle approximation assumes that the velocity and path length of the electron remains constant through the foll. The assumptions are valid for sufficiently thin foils. In addition to befing scattered, an electron deposits energy and slows down as it passes through the fall. The amount of energy deposited by an electron in a pass through the foll 1. determined from tabular stopping power values. 22

We have used several Monte-Carlo models to study electron deposition which can be divided into the following categorles: (I) collisional deposition only; (2) collisional deposition in the presence of specified electric and magnetic fields and (3) collisional deposition with selfconsistent magnetic flelds. In all these cases elther a diode code ca1culation or information from an experiment must be used to choose the Bource beam parameterc.

The simplest Monte Carlo code (collisional deposition only) is represented by a $1-D$ model TIGER ${ }^{23}$ and a 2-D model CYLTRAN. 24 These models are well-documented and are applicable for cases where flelds are 
not Important and transport of the beam electrons are collision dominated, as would be the case for a thlck high density target. A more complex code included the effects of strong electric and magnetic flelds on deposition, although the cholce of the flelds is only representative of the true fields and are not self-consistent. This model was previously discussed in Ref. 20 and more recently documented as a more complete model called CYLEM. ${ }^{25}$ The third code type respresents an attempt at selfconsistency. This mode1 ${ }^{26}$ uses an iterative procedure to converge on a steady-state solution that includes self-consistent beam-target interaction. One can study the effect of scattering on the self-field of the beam with this model, although the choice of the infected beam is somewhat arbitrary.

The Monte Carlo models then predicted spectfic power deposition for a given set of source beam parameters. This deposition was then included as an energy source term in a hydrodynamic model CHART-D to calculate the experimental abservables which Include material temperature and blowoff. Spectfic power deposited $P_{m}(W / g m)$ is $g 1$ ven by the following relation;

$$
P_{\mathrm{m}}=\int_{E_{\max }}^{0} e F(E \beta c s(E) d E \text {, }
$$

where $e=1.6 \times 10^{-19}$ coul, $F(E)=$ energy distribution of electrons $\left(\mathrm{cm}^{-3} \mathrm{ev}^{-1}\right), \quad c=$ electron speed, $\mathrm{S}(E)=$ electron stopping power $\left(\mathrm{eV}-\mathrm{cm}^{2} / \mathrm{gm}^{\mathrm{m}}\right)$, and $\mathrm{E}=$ electron energy which ranges between $0 \leq \mathrm{E} \leq \mathrm{E}_{\text {trax }}$. The beam density is given as

$$
n_{b}=\int_{0}^{E_{\max }} F(E) d E .
$$


Thus, for a monoenergetic beam, which 18 of ten approximately true for thin target deposition, we have

$$
P_{m}=e n_{b} \beta c S=X J S
$$

where $X=$ enbancement factor $=\beta c /\left\langle v_{D}\right\rangle$ where $\left\langle v_{D}\right\rangle$ is the normal electron drift velocity, and $J$ the normal current density (amps $\left./ \mathrm{cm}^{2}\right)$. EXPERIMENTAI,

The experimental data were obtained on the Sandia Laboratories' Hydra and Proto-I acceieratars. The Hydra accelerator was operated with a peak Inductively corrected voltage and current of $950 \mathrm{kV}$ and $600 \mathrm{kA}$. Figure la shaws the total current and inductively corrected voltage in the diode for the Hydra experiments. The FWHM of tive power pulse was 60 nsec. A $15 \mathrm{kV}$ peak-to-peak prepulse with a $40 \mathrm{MHz}$ oscillation was applied to the diade for 700 ns prior to the main pulse. The diode and experimental set-up used with the Hydra accelerator are shown In Fig. 2. The cathode surface was grooved brass and sprayed with Aerodag G. 27

The Proto-I accelerator was operated with peak voltage and current of $1.5 \mathrm{MV}$ and $250 \mathrm{kA}$. The FWHM of the power pulse was $20 \mathrm{~ns}$. Figure $1 \mathrm{~b}$ shows the total diode current and inductively corrected voltage in the Proto-I experiments. The prepulse voltage and current on the Proto-I acce1erator were $10 \mathrm{kV}$ and $100 \mathrm{~A}$ for $700 \mathrm{~ns}$, plus $20 \mathrm{~ns}$ of high frequency, less than $1 \mathrm{kA}$ current and $100 \mathrm{kV}$ prepulse, prior to the main pulse. The cachode surface was smooth brass and sprayed with Aerodag. Figure 3 shows the diode and experimental set-up used with the Proto I accelerator. The gold foil anode thicknesses on both accelerators were $50.8,25.4,12.7$ and $6.4 \mu \mathrm{m}$. The aluminum foll anode thicknesses were $205.7,88.9,38.1$, and $6.4 \mu \mathrm{m}$. 

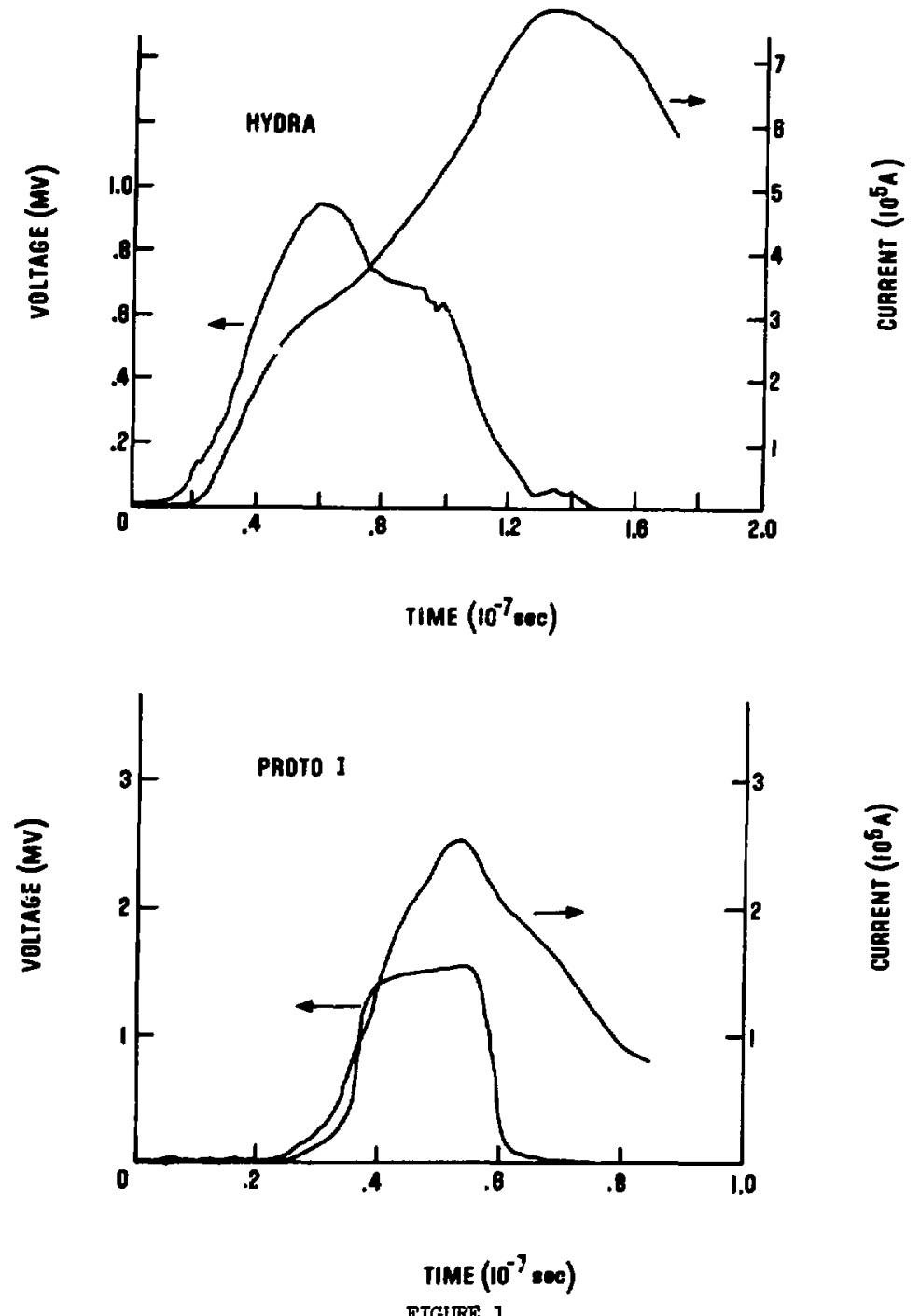

Total diode current and inductively corrected diode voltage for (a) Hydra experiments, and (b) Proto-I experine nts. 


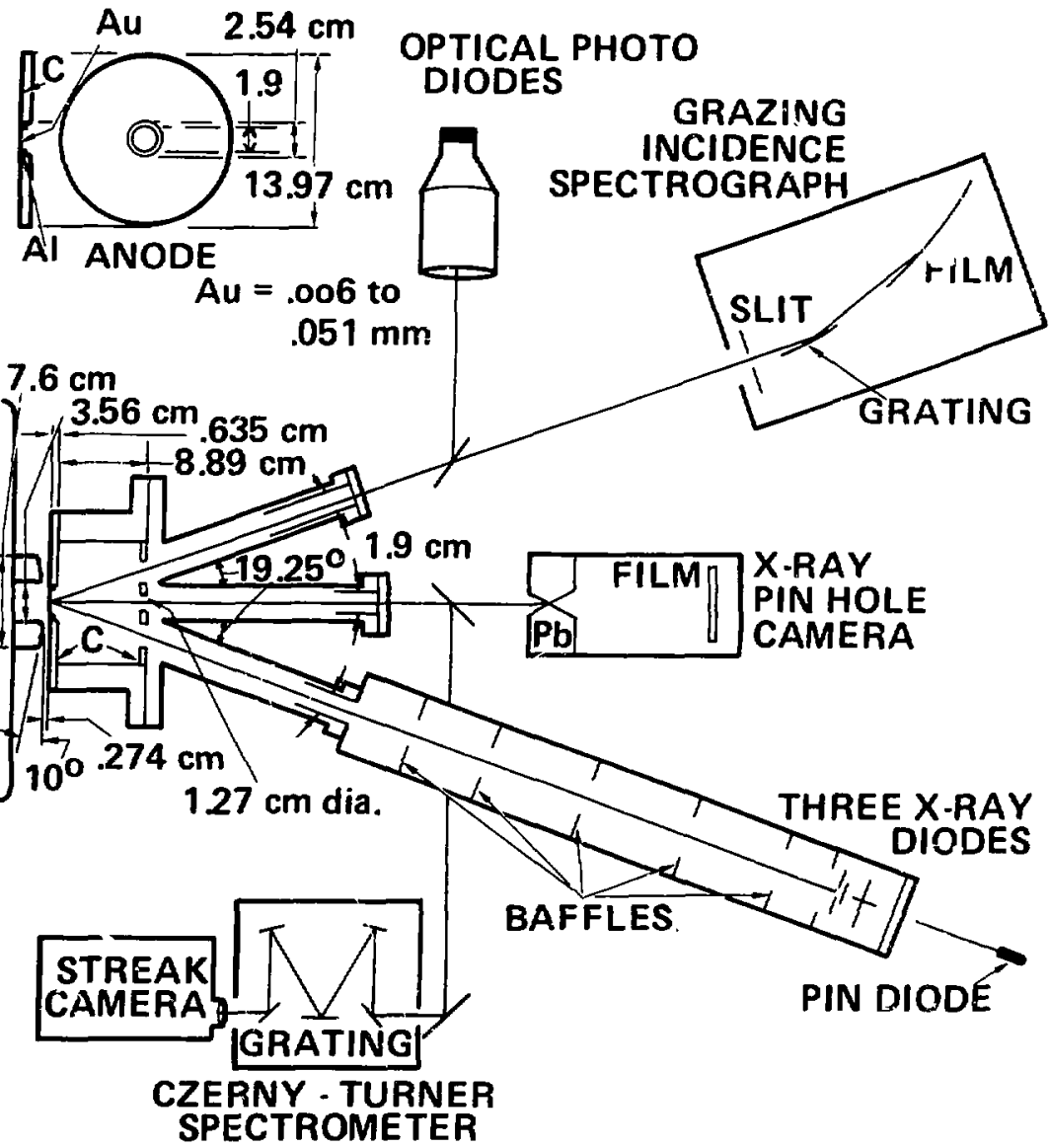

HYDRA

FIGURE 2

Hydra diode and experimental chamber. 


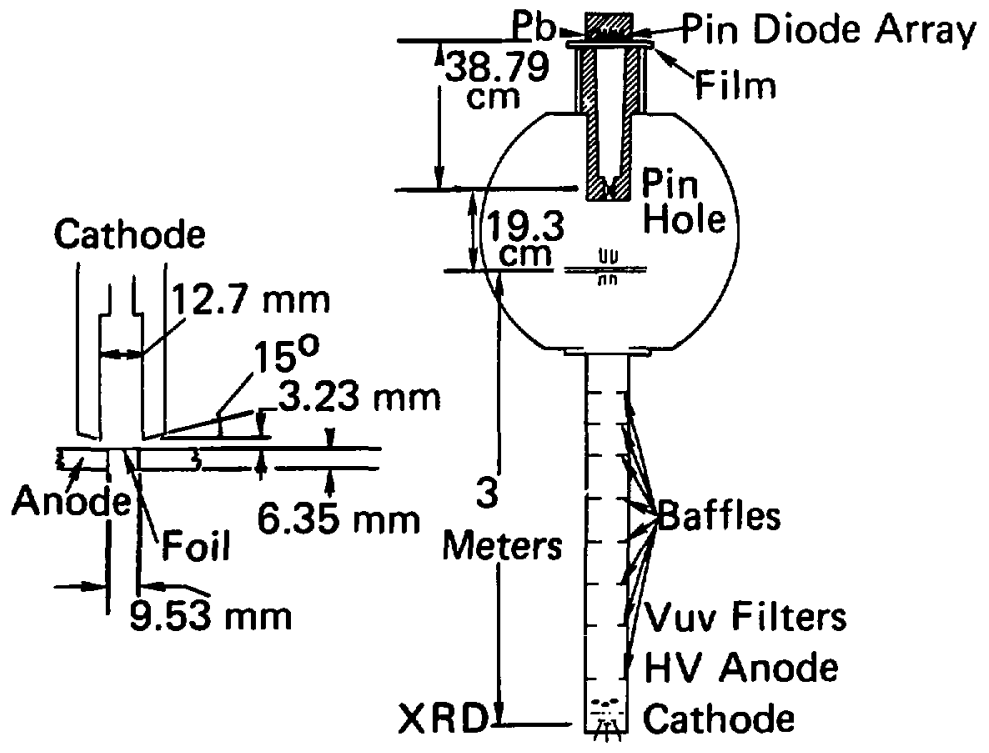

FIGURE 3

Proto-I diode and experimental chamber. 
The current density as a function of radius from the center of the pinch was deduced from the hard $x$-ray intenalty of the 1mages on a plahole camera system located normal to the anode. On tne Proto-I accelerator, pinhole photgraphs of the hard $x$-ray fluences were taken from both sides of the anode but not simultaneously on the same shot. The plnhole consisted of depleted uranium, slug, $5 \mathrm{~cm} 10 \mathrm{gg}$, with a $250 \mu \mathrm{m}$ aperture and a cone angle of $6^{\circ}$. The $x$-ray fluences were recorded on absolutely callbrated photographic f1lms, Kodak types $M$ ane AA. Relative cal1brations of NS, NS intensified, and AA lead pack, were normalized to $M$ and AA. Polarold type 57 intensifled was also used. The 1ntensifying screens were Rarex BG high speed. The calibrations were performed on the Pelletron DC electron beam machine. Monoenergetic electron energies from 0.4 to $1.1 \mathrm{MeV}$ can be delivered on the Pelletron with currents up to $8 \mu \mathrm{A}$. Renormalization was obtalned by comparison of the x-ray dose to the film with predictions of $x$-ray generation using coupled electron-jhoton Monte Carlo codes. The pinhole Images were filtered with Lucite to provide 80 percent of the response (ten percent to ninety percent) in photons with energies of 30-160 keV. The assumptions made in deducing experimental current: density were that if an electron made more than a single pass through the foll, it re-entered the foll at the same radial position it left (one-dimensional) and that the inftal electron angular distribution was cosinuosoldal and constant as a function of radius. This may overestimate the number density on axis by as much as 20 percent for the low $Z$ aluminum folls. 28

To obtain the apparent incident current density $\mathrm{J}\left(\mathrm{amps} / \mathrm{cm}^{2}\right.$ ) for a cold, cosinusoldal angular distribution with a local macroscopic elc itric flald in the diode only, we took the current density from the pinhole 
photographs except that this time we normalized to the total current as neasured by the $d B / d t$ monitors, corrected for ton current. The $d B / d t$ monitors measure the total dlode current, not just the target current. The apparent target current w11 be less than or equal to the target current. The Ion current was salculated from the models of Creedon, ${ }^{29}$ Goldstein, ${ }^{30}$ and Poukey. 31 Fi: total current in the diode was given by the parapotential flow model as

$$
I_{p}=I_{e}+I_{1}=8500(R / d) \gamma \ln \left(\nu+\sqrt{\gamma^{2}-1}\right)
$$

where R/d was taken to be the Initial geometrical radius and anode-cathode separation, $\lambda$ is gtven by $1+e V / M c^{2}, V$ is the voltage in the diode and m is the rest mass of an electron. The ratio of Ion (proton) current to electron current was given by

$$
\frac{I_{1}}{I_{e}}=0.033 \frac{\gamma}{\sqrt{\gamma+1}} \frac{R}{d}
$$

$\nu / \gamma$ for an electron beam, we define as tìe total current within the FWH of the deposition profile divided by the Alfven current. 37 That is,

$$
\frac{\nu}{\gamma}=\frac{I(\mathrm{kA})}{17 \beta_{\mathrm{L}}{ }^{\gamma}}
$$

where I 18 the total current within the FWHM of the deposition profile and $\boldsymbol{\beta}_{\mathrm{L}} \mathrm{C}$ is the component of beam velocity along the axis of oymmetry. $\gamma$ 1s $\left(1-\beta^{2}\right)^{-1 / 2}$ where $\beta$ C is the beam velocity.

The total current in the pinch region was deduced from absolutely callbrated PIN detector, apertured to view only the central 2 cIl diameter area. The PINs were calibrated absolutely on the Pelletron, behind $150 \mu \mathrm{m}$ 
uranium, $250 \mu \mathrm{m}$ erbium, $50 \mu \mathrm{m}$ copper and $300 \mu \mathrm{m}$ aluminum filters to allow an essentially flat response for incldent radiation. The one-dimensional electron-photon transport code TIGER was usid to calculate the resuiting photon spectrum. Figure 4 shows the spectral and total energy response of the PINB. The PIN detector 1 tself was surrounded with $0.5 \mathrm{~cm}$ thick gilicon arid aluminut to provide electronic equilibrium to the Compton scattered electrons, that 18, a "Bragg-Gray" cavity. This 18 analogous to the principle of the "air-walled" Ionization chamber. 32 This entire packepe was then mounted in a lead chamber to shield against scattered $x$-rays. On the Hydra accelerator, a single-apertured PIN was mounted behind the photoelectric dlodes or $x$-ray diodes (XRDs) ut1lizing thetr brass baffling system. On the Proto I accelerator, the apertured PIN was mounted in place of the pinhole assembly and utilized the lad baffled housing. On the gold foll anode shots, on Proto I, an array of apertured PINa were mounted on the image plane of the pinhole camera without their high band pass filters for relative current density measurements. The diameter of the 1ndividual PINs was $1 \mathrm{~mm}$ and the center-to-center distance between PINs was 4 mm. Ori the aluminum shots, however, the x-ray flux was Insufficient to allow the array of PINs to be wounted on the Image plane of the pinhole camera system.

Radiation temperature measurenents were made w1th a triplet array of aluminum cathode XRDs which were operated windowless, with a $0.75 \mu \mathrm{m}$ aluminum filter, and with a $0.33 \mu \mathrm{m}$ parylene $\left(\mathrm{C}_{8} \mathrm{H}_{8}\right)$ filcer. ${ }^{33}$ The XRDs viewed the source through a serles of baffles to prevent scattering off of the walls of the diagn tic tubes. The XRDg gave remporal information In the energy ranges from 5 to $25 \mathrm{eV}$ (unfiltered) 25 to $75 \mathrm{eV}(0.75 \mu \mathrm{m}$ alumInum), and 75 to $284 \mathrm{eV}(0.33 \mu \mathrm{n}$ parylene). Figure 5 shows the cathode 


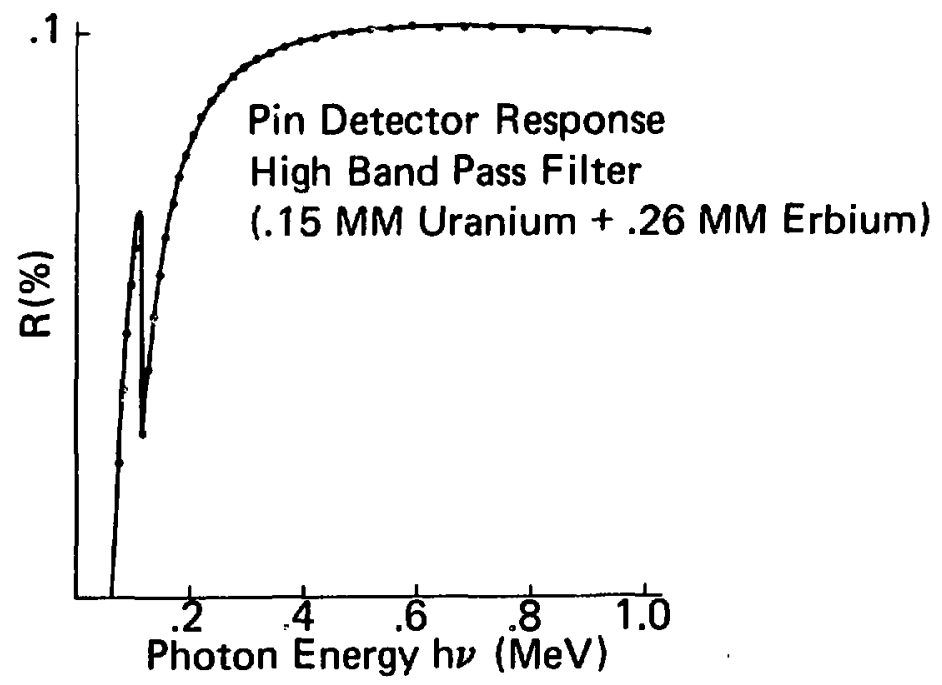

FIGURE 4

Spectral and total - friclency respones of PIN detector behind $150 \mathrm{micron}$ thick Uranium, 250 micron thick erbium, 50 micron thick copper, and 300 mieron aluminum filters. 

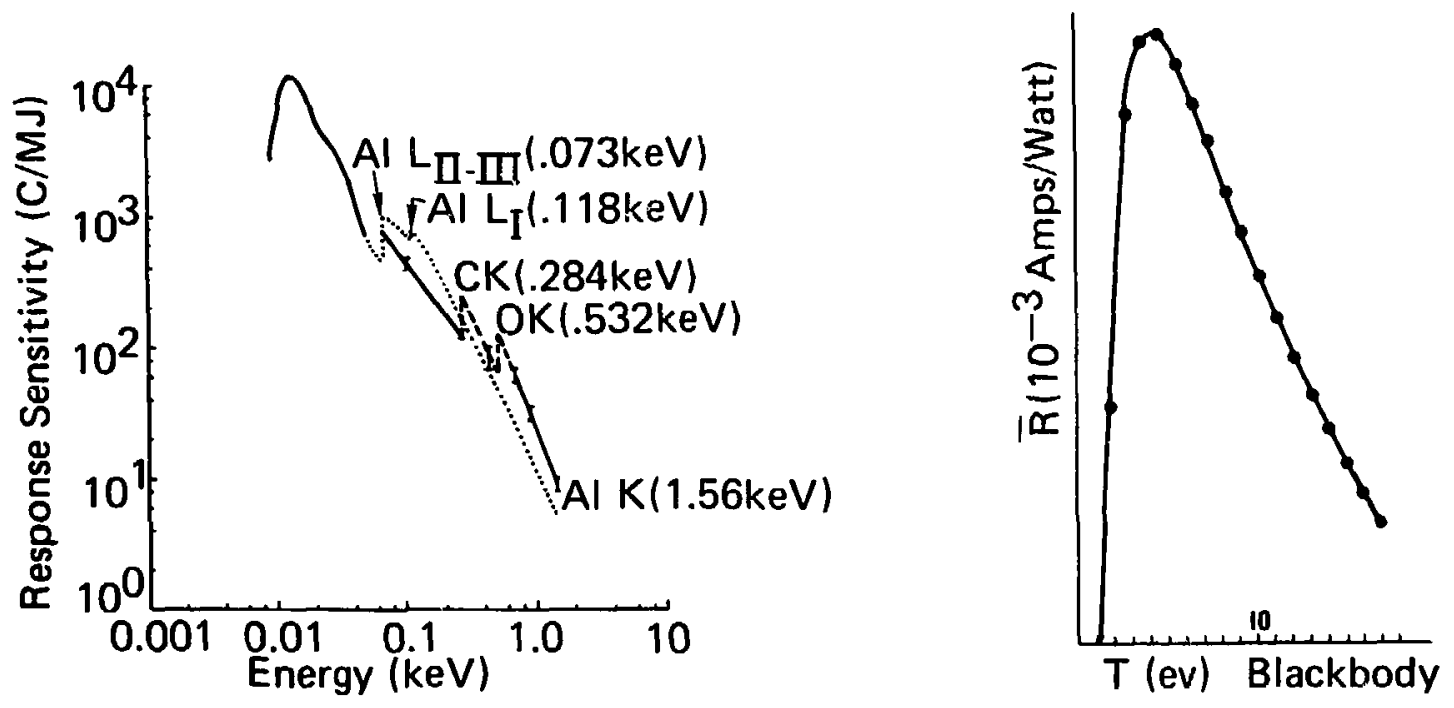

FIGURE 5

Cathode response of aluminum XRD and response as a function of blackbody temperature, where

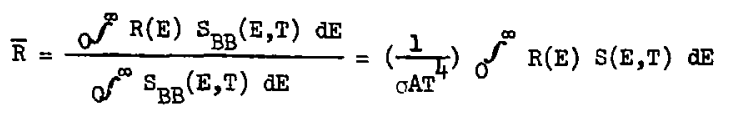


response of the XRDs as a function of blackbody temperature. Between 3 and $7 \mathrm{eV}$ blackbody cemperature, the response of the unfiltered XRD varies only 20 percent. The dutectors are insensitive to radiation temperatures below $2 \mathrm{eV}$. The XRDs were located approximately 3 meters away from the source on Proto I to separate the radiation from the ton emission coming from the anode. Magnets were placed in the dlagiostic tubes on the Hydra experiments to elim1nate electron emission coming from the cathode through the anode.

Because of the small detector solid angle necessary for separation of radiation and ion emiscion, the Proto-I experiments required temperature measurements based on the unflltered XRO only. For the unfiltered XRD, the response of the detector is proportional to $T^{4}$ as discussed above (see F1R. 5). For a radlating disk with a detector at normal incidence, the blackbody radiated power is given by

$$
P_{B B} \approx 2 \sigma A(T(t))^{4}\left(\frac{d \Omega}{2 \pi}\right)=\frac{v(t)}{50} \frac{1}{\bar{R}(T)}
$$

where $\left(\frac{d \Omega}{2 \pi}\right)$ is the fractional solld angle radiated into $2 \pi$ steradians, - is the Stefan-Boltzmann constant, $R(T)$ is the detector response sensitivity which is approximately a constant (see Fig. 5) in units of amps/wate, $V(t)$ Is the voltage as measured by the detector, and $A$ is the source area. In estimating the oinimum radiation temperature, the diameter of the radiating region was chosen to be $2 \mathrm{~mm}$ greater than the FWH of the hard $x$-ray prof $11 \mathrm{e} .^{13}$ Because of the $T^{4}$ dependence of the radiated power, the resultant temperature $1 \mathrm{~g}$ insensitive to the exact area of enission. Optical temperature measurements were made with an absolutely calibrated silicon photodlode. The optical photodiode was filtered to a $70 \mathrm{~nm}$ bandw1th at $507 \mathrm{~nm}$, and had a calculated response proportional to $\mathrm{r}^{1.9}$ for a blackbody radiation source in the temperature region of interest. 
Because of the weaker cemperature dependence, the accuracy of the emitting area becones wore critical. A questar telescope was used to Image the central $0.05 \mathrm{~cm}^{2}$ of the deposition region through a pinhole to the optical photodfode. The entlre opt1, al system was aboolutely callbrated with a tungsten lamp at $507 \mathrm{~nm}$. Optical photodlode measurements were taken B Imultaneously with XUV measurements with XRDB on the Hydra experiments. The diode geometry prevented simultaneous measurements on the Proto-I experiments.

Valfdity of the blackbody assumption was a critlcal question in the analysis of these experiments. To this end, the foll heating and expansion was gimulated with the CHART $\mathrm{D}^{14}$ radiation-hydrodynamic code and compared wth opacity calculations..$^{34}$ The results of a typical case are displayed In Fig. 6 for a $25 \mu$ thick gold foll with a $1 \mathrm{TW} / \mathrm{gm}$ deposition rate. The temperature and density profiles, measured fruin the foll center plane, are given as simulated at the end of the power pulse with values corresponding to the left-hand ordinate. Photon escape functions.

$$
\exp \left(-\int_{x}^{\infty} k(\rho, T) d x\right)
$$

on the right-hand scale, describe the percentage of optlcal $(2.5 \mathrm{eV})$ or average XUV (20 eV) photons escaping from a given depth. It is clear that the expanded foll is st1ll opaque for these photons and that both systems see Into reglons of the same temperature, although differing densities. These similations also allow an estimate of the intertor temperature to be made based on surface temperature weasurenents. Time Integrated XUV spectra were obtained with a 3001 ine/mm concave diffraction grating mounted on a $2.2 \mathrm{~m}$ Rowland circle, grazing incidence spectrograph. The spectrograph was mounted in place of the optical photodiode on the Hydra accelerator for the gold foll experiments. The 


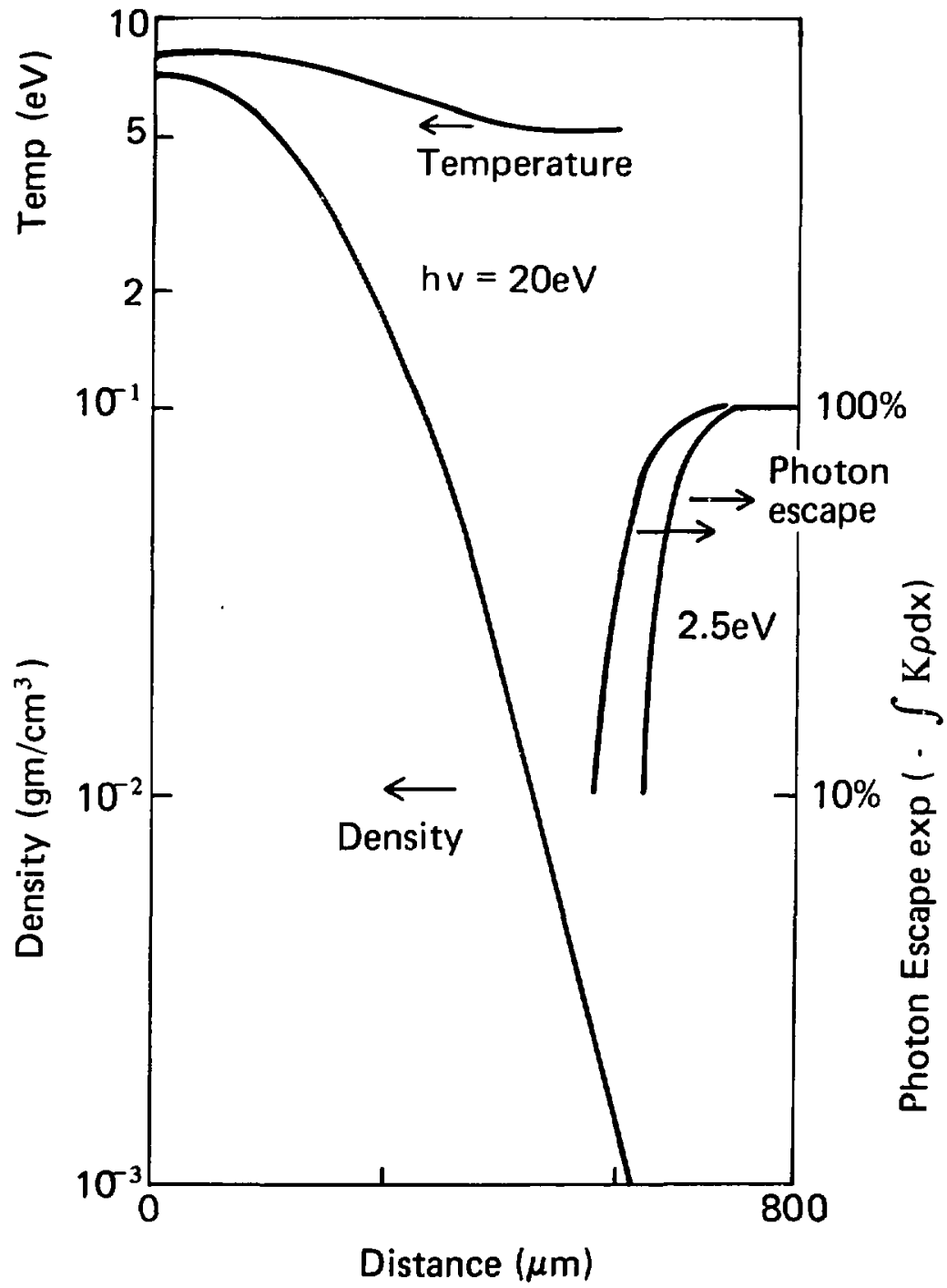

\section{FIGURE 6}

Temperature, density, and photon escape functions vs. distance into a $25 \mu^{m}$ thlck gold with a $1 \mathrm{TW} / \mathrm{gm}$ deposition rete utilizing the radiation-hydrodynamic code CHART $\mathbf{D}$. 
spectrograph was located approximately 1 m away from the source. The zensitivity of the spectrograph, phocographic plate combination was not sufficlent to observe continuum emission on a single shot. In particular, th1s instrument was used to check the validity of the blackbody radiation assumption. If any gold $N$ or $O$ plasma line emission were observed, the assumption would be Invalid. The energy region of $10 \mathrm{eV}$ to $1 \mathrm{keV}$ observed with tilis instrument was colncident with the spectral region of the time resolved XRD measurements from which temperature measurements were deduced.

Simflarly, time resolved optical spectral measurements were made on the Hydra, gold foll experiments. The spectrometer system consisted of a Cerny-Turner optical spectrograph coupled to an image converter canera. The optical spectrometer was capable of viewing $70 \mathrm{~nm}$ between 245 and $700 \mathrm{~nm}$ on a given shot. This syetem was employed to verify the blackbody radiation assumption at $507 \mathrm{~nm}$ where the optical photodiode temperature measurements icie made. In addition, different spectral measurements In other parts of the spectrum were utilized to determine the effective Ionization species of the expanding plasma. HYDRA EXPERIMENT

A. Experimental Results

F1gure 7 shows the apparent incident current density based on pinhole photographs on the Hydra experiments. The total incident current was normalized to the $\mathrm{dB} / \mathrm{d}$ t monttors corrected fot lon current as discussed in the last section. The curves to the left give the apparent incident current density as a function of radius, while the curves to the right give the total apparent incident current in the pinch region as a function of radius. The term "apparent incldent" current was used to denote the fact 


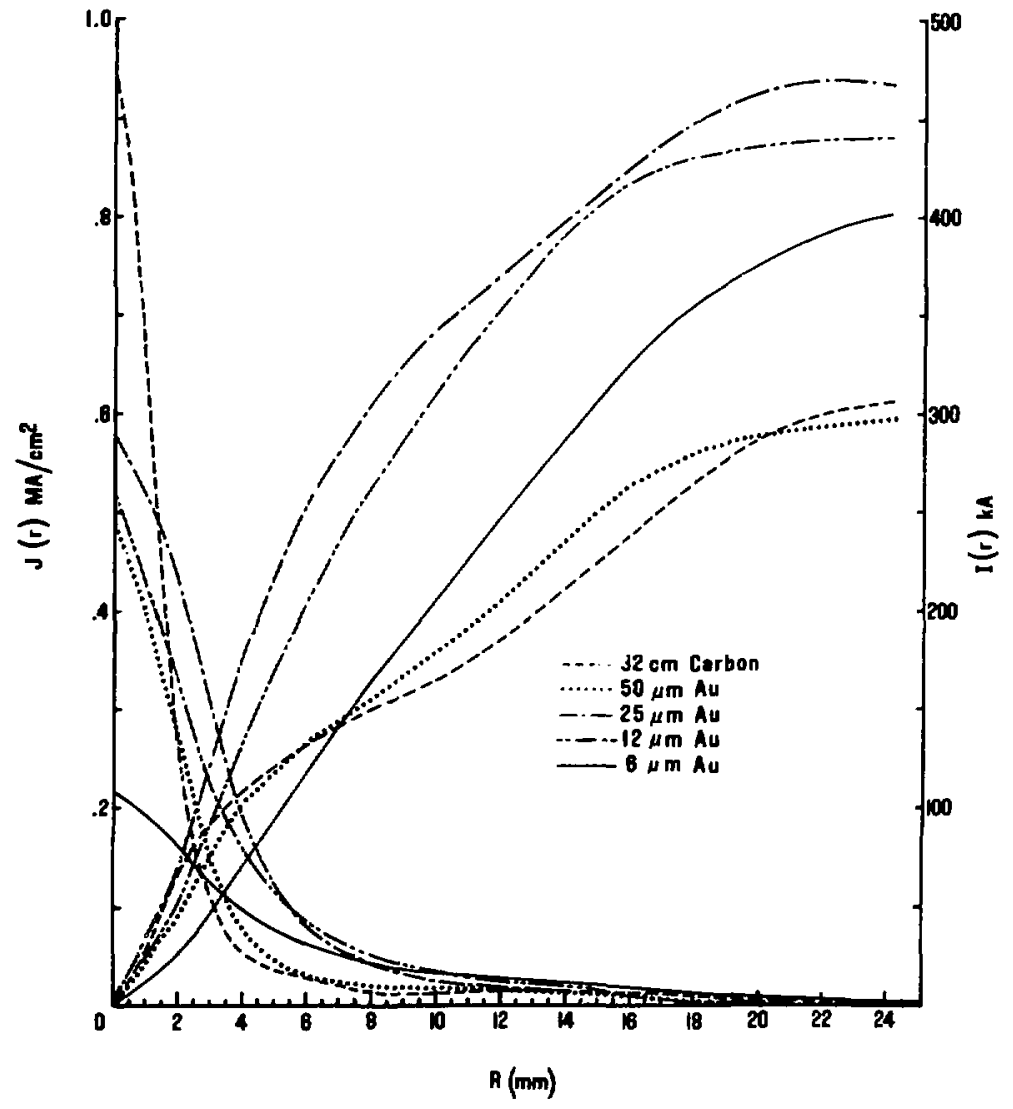

FIGURE 7

Current density and total current vs. radius for $0.32 \mathrm{~cm}$ carbon $50,25,12.7$, and $6.4 \mathrm{um}^{\mathrm{m}}$ thick gold on the Hydre experiments. 
that the $x$-ray flux was normalized to single electron passes through the foll from the $\mathrm{dB} / \mathrm{dt}$ monicors and did not consider two-dimensional effects. The apparent current densitles were for $0.32 \mathrm{co}$ thick ATJ graphite, $50 \mu \mathrm{m}$, $25 \mu \mathrm{m}, 12.7 \mu \mathrm{m}$, and $6.35 \mu \mathrm{m}$ thlck gold folls. Anparent peak current densities as high as $0.9 \mathrm{MA} / \mathrm{cm}^{2}$ were observed for graphite, while apparent peak current denstities as low as $0.2 \mathrm{MA} / \mathrm{cm}^{2}$ were observed for $6.35 \mu \mathrm{m}$ thick gold. The trend appeared to be that the thinner the foll, the greater the FWHM of the hard x-ray deposition profile, and the lower the apparent peak current densfty for a given incident current. Figure 8 shows the total current in the diode inferred from $\mathrm{dB} / \mathrm{dt}$ measurements (as a function of time) as compared to the calculated current in the pinch from the apertured PIN detector. The signal strength is Integrated assuming a cosinuboldal (average angle of $45^{\circ}$ ) angular distribution and a single pass electron beam. The total current measurements we:e for the Hydra experiments with $50,25,12.7,6.4 \mu \mathrm{m}$ thick gold folls. The general trend appeared to be that the thinner the foll, the greater the calculated plach current for a given incldent current. In the cases where the calculated current was less than the total diode current, we conclude that not all the current in the dlode got to the center pinch region. However, the possibility of some multiple passes or recirculation of electrons cannot be ruled out. In the case of the $6.4 \mu \mathrm{m}$ thick gold, though, the calculated current in the plnch region exceeds the net total diode current. Therefore, in the case of $6.4 \mu \mathrm{m}$ thick gold, each beam electron makes more than a single pass through the foll. Since the bremsetrahlung coming from the foll ts very much peaked in the observer's direction, we infer that electrons re-enter the foll from the diode side 


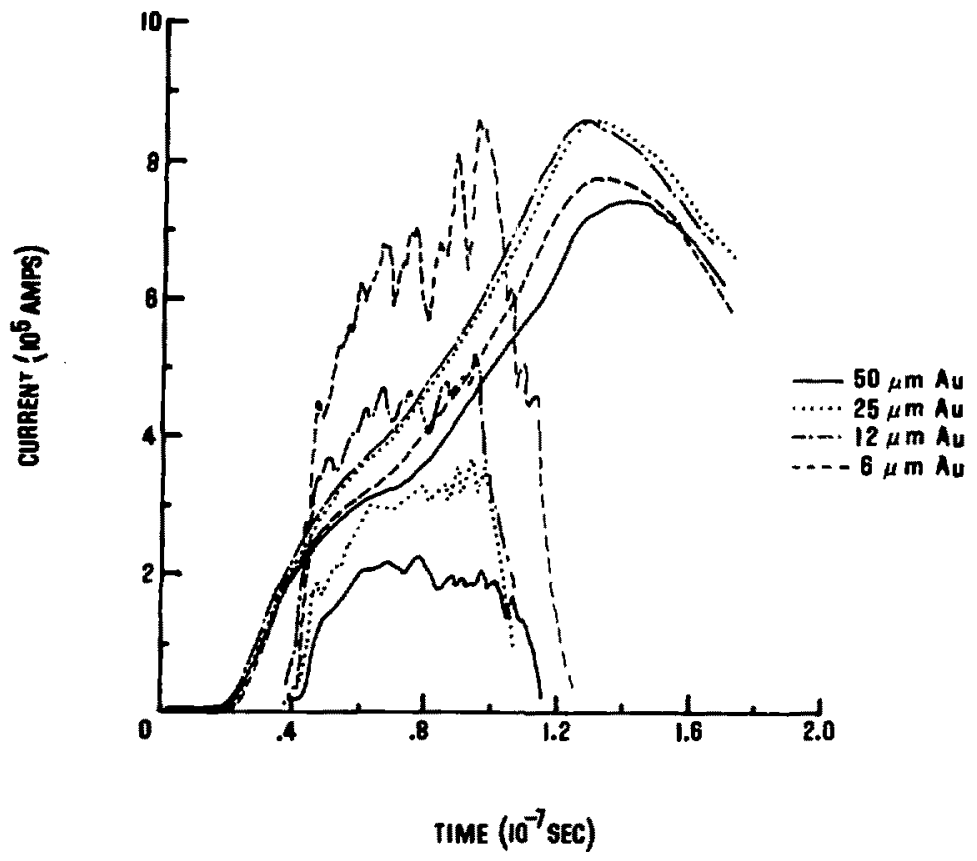

FIGURE 8

Total current in the diode and effective current in the piach for single pass electrons vs. time for 50, 25, 12.7, and 6.4 um thick gold on the Hydra experiments. 
roughly two times on the average. This evidence for enhanced $x$-ray flux 18 also evidence for enhanced deposition for $6.4 \mu \mathrm{m}$ thick gold.

F1gure 9 shows the temporal history of the hard x-ray, XUV and optical radiation diagnosties for experiments on Hydra. The hard x-ray signal given by the PIN detector is colncident with the power pulse in the diode. The streak time is that given by the optical spectrometer and image converter camera system. The temperature at 507 mo is that given by an absolutely calibrated photodiode behind an interference filter. The XUV temperature is that glven hy the absolutely calibrated XRD utilizing no filter and assuming a source area of $1 \mathrm{~cm}^{2}$. Th1s particular shot on the Hydra accelerator was for a $6 \mu \mathrm{m}$ thick gold foll anode. Also shown is a comparison with a calculation utilizing the radiation-hydrodynamic, Lagranian code, CHART D. ${ }^{14}$ The code used the average deposition given by the electron-photon, condensed history Monte-Carlo code TIGER, ${ }^{3}$ tncluding the time integrated electron spectrum for the particular shot. The average electron deposition in $6.4 \mu \mathrm{m}$ gold for this particular shot was $3.6 \mathrm{MeV} / \mathrm{cm}^{2} / \mathrm{g}$ for a cosinusoidal angular distribution of incident electrons and a local macroscopic electric field in the diode given by the corrected voltage. The closest fit to the experimentally measured temperature was a peak spectflc power of $1 \mathrm{TW} / \mathrm{g}$. Th1s corresponds to a peak current density of approximately $0.28 \mathrm{MA} / \mathrm{cm}^{2}$ as compared to an apparent inctdent current density of $0.21 \mathrm{MA} / \mathrm{cm}^{2}$ (see Fig. 7). Equivalently, 9.9 percent of an average electron's energy was depostted in the foll compared with an expected 7.6 percent for a single electron pass.

Figure 10 shows the temporal history of the radiation temperatures for three shots w1th 50,25 , and $12.7 \mu$ m thick gold foll anodes on the 


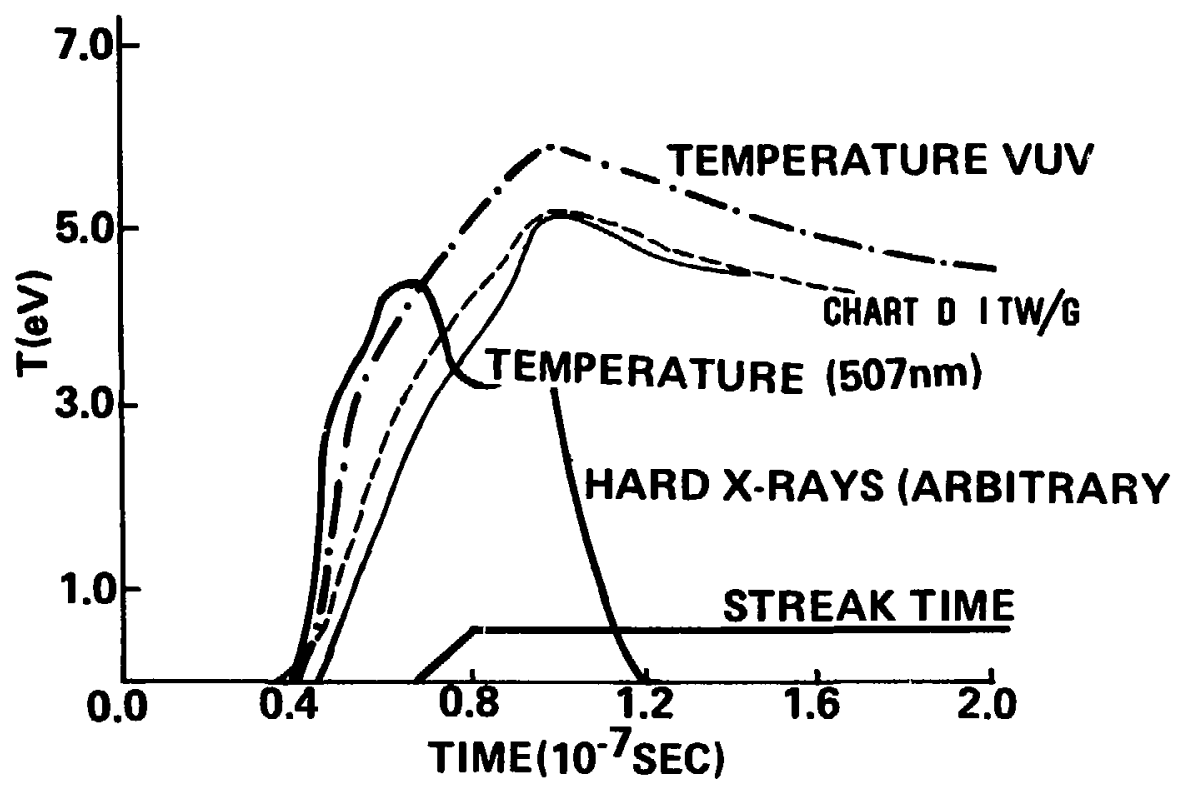

FIGURE 9

Temporal history of the hard $x-r a y$ flux, optical streak spectrum, XWV and optical temperature, and theoretical CHART D prediction for $6 \mu$ m thick gold on the Hydra accelerator. 


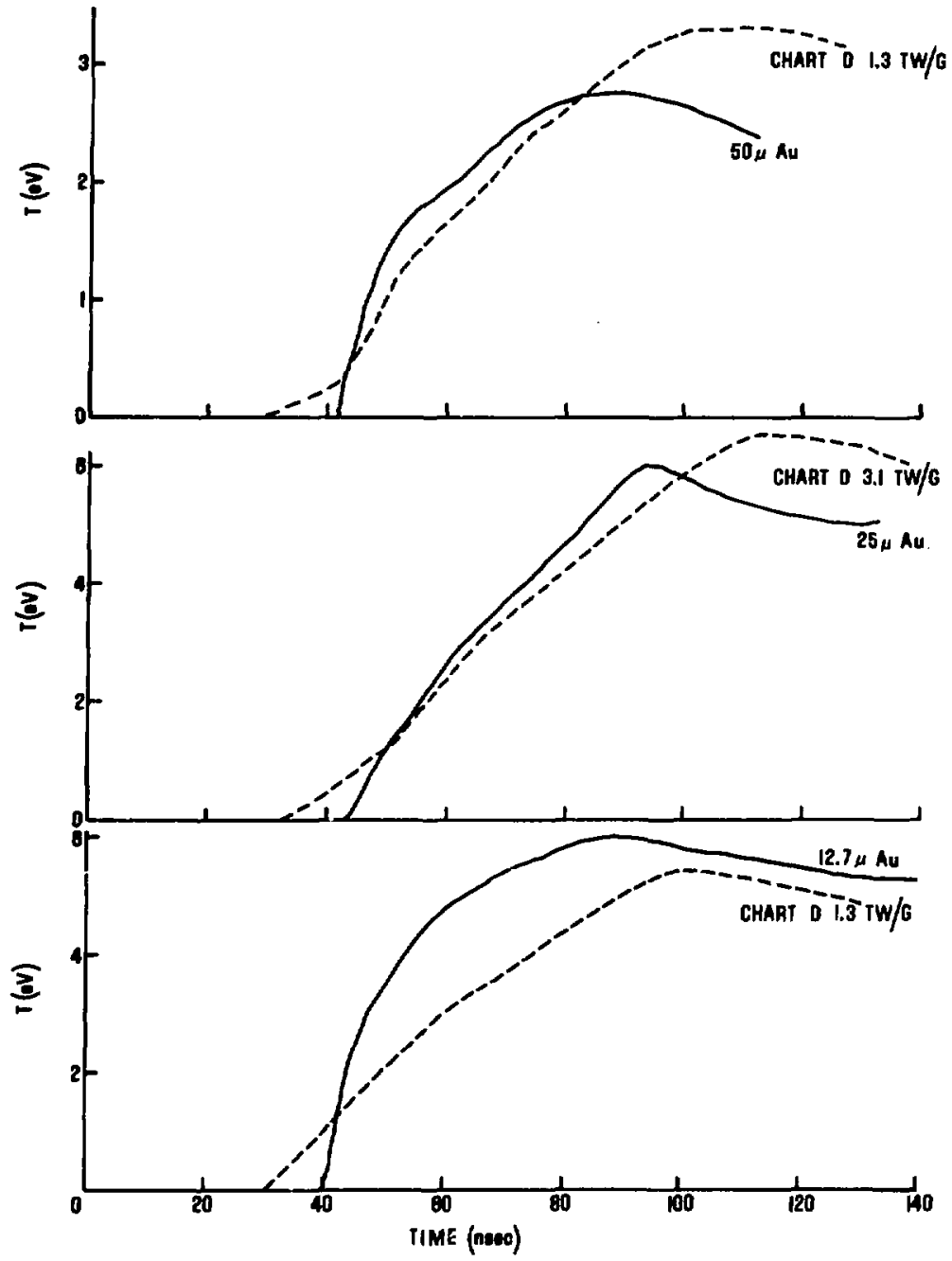

FIGURE 10

Temporal history of the XUV radiation temperature conpared with theoreticel CHART D predictions for 50,25 , and $12.7 \mu$ thick gold foils on tue Hydra accelerator, 
with no f1lter, and source areas of approximately $0.5 \mathrm{~cm}^{2}$. The temperatures were compared with the calculations from the code CHART $D^{14}$ as described above. The average deposition per electron was $4.8,5.1$, and $4.2 \mathrm{MeV} / \mathrm{cm}^{2} / \mathrm{g}$ for the above thickness folls, based on the respective electron spectra for these shots. The closest fit to the experimentally measured temperatures were peak speciflc powers of $1.3,3.1$, and $1.3 \mathrm{TW} / 8$, rspectively. These peak spectific powers correspond to peak current densities of 0.25 , 0.62 , and $0.3 \mathrm{MA} / \mathrm{cm}^{2}$, respectively. No special significance should be attached to the $25 \mu \mathrm{m}$ thick gold shot other than that the total 1mpedance In the diode was lower for this particular shot and consequently the total current in the plnch was higher. These experimentally deduced peak current densities were equal to or less than the apparent incident peak current densittes as measured from the hard $x$-ray fluences (see Fig. 7). Since the peak specific powers and x-ray flux from the pinch were less than or equal to the apparent incident current density on 50,25 , and $12.7 \mu \mathrm{m}$ thick gold, we can only conclude that less than 100 percent of the current In the diode made $1 \mathrm{t}$ to the pinch region. The peak current densities are consistent with the x-ray pinhole profiles, where the total current in the pinch was normalized to the results of the PIN measurements (see Fig. 8).

Figure 11 compares the temporal response of the unfiltered XRD, the $0.75 \mu \mathrm{m}$ thick aluminum filtered $\mathrm{XRD}$, and the $0.33 \mu \mathrm{m}$ thick $\mathrm{C}_{8} \mathrm{H}_{8}$ filtered XRD for $6 \mu \mathrm{m}$ thick gold foil on the Hydra experiment. The Intensity rat1os between any pair of XRDs were consistent with the 3-6 eV temperatures measured from the unfiltered XRD. However, these ratios are very gengitive to the thicknesses of the XRD filtering folls as well as their photon absorption cross sections. The aluminum foll thicknesses varied anywhere from 0.5 to $1 \mu \mathrm{m}$ in thickness. Each foll was weighed prior to 


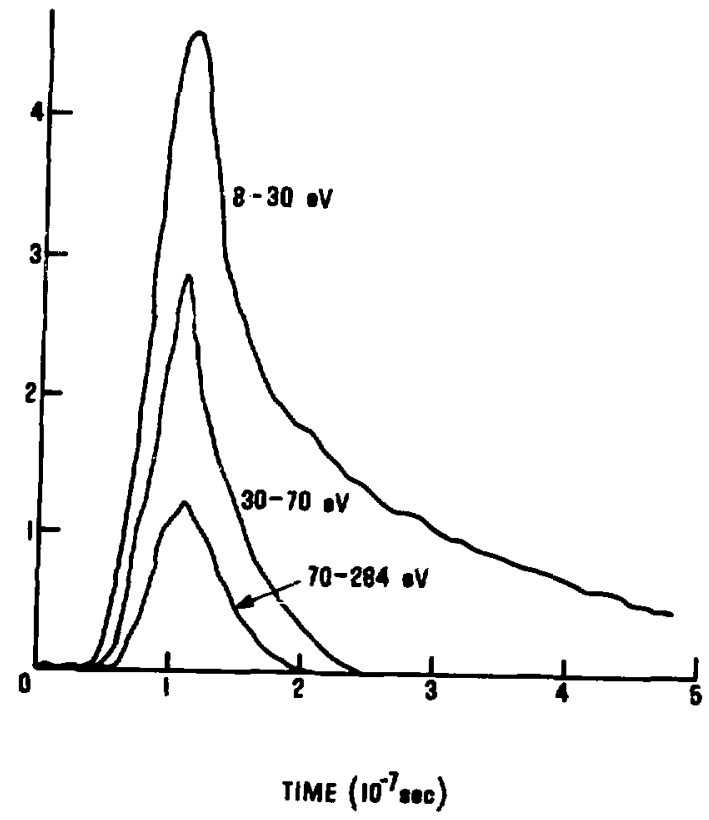

FIGIRE 11

Temporal history of the XUV radiation diagnostics for 8-30 eV (bare XRD), 30-73 eV ( 0.75 micron Al), and 73-284 eV ( 0.33 micron $\left.\mathrm{C}_{8} \mathrm{HB}\right)$ for 6 um sold Folls on the Hydra accelerator. 
use and foll uniformity was assumed. Roughly, the ratiog between the unfiltered XRD and the $0.75 \mu \mathrm{m}$ aluminum filtered XRD was 100:1 and the rat10 between the $0.75 \mu \mathrm{D}$ aluminum $X R D$ and the $0.33 \mu \mathrm{m}$ parylene $\left(\mathrm{C}_{8} \mathrm{H}_{8}\right)$ XRD was 3:1 in the temperature regton of interest and were consistent with a single blackbody temperature.

Table I I Ists the XUV line emission taken with a $300 /$ mon grating in a grazing Incidence Bpectrograph for the Hydra experimentts with a $6.4 \mu \mathrm{m}$ foll anode. The spectra were obtained between 10 and $80 \mathrm{~nm}$. No emission lines from gold were observed on any of the gold foil shots. Only contaminant lines from primarlily oxygen were present. On this particulat shot, these IInes were coinctdent in energy with the aluminum and parylene filtered XRDs which appeared, in time, at the collapse of the diode 1mpedance at the end of the power pulse. Therefore, we can be reasonably sure that the spectrum is dominated by continuum earlier in time. Unfortunately, we did not have sufficient intensity to observe the continuum directly, since the entrance sl1t to the spectrograph was located more than a meter away from the source.

Figure 12 shows the time resolved aptical spectra abserved in the spectral region between 245 and $315 \mathrm{~nm}$ for $6.4,12.7$, and $50 \mu \mathrm{m}$ thick gold on the Hydra experiments. Only continuum was observed during the time of the power pulse (see FIg. 8). However, after the power pulse was turned off, numerous absorption lines from neutral and single lonized gold were observed. No absorption lines were observed in the spectral region around $507 \mathrm{~nm}$. However, this does suggest that the blackbody assumption was breaking down in some parts of the spectrum after the power pulse was turned off. We have no evidence to suggest that the blackbody assumption was not valid during the power pulse. The late time plasma, however, 
TABLE I

Contaminent XUV Ifne emission. Au targets

Wavelength (nm)

$$
16.4
$$

18.3

19.8

23.7

27.2

30.0

37.4

55.3

61.6

74.1

74.8
Iontc Species

ov

OIV

ov

OIII

oIv

OIV

OIII

OIV

OIII

OII

OI 


\section{$6 \mu \mathrm{FOIL}$}

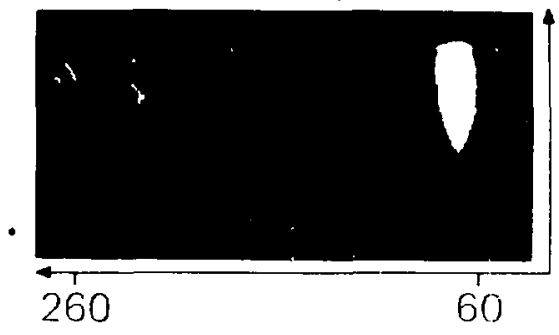

WAVELENGTH

LINE

1.

2.

3.

4.

5.

6.

7.
(:)

2954.2

2822.6

2748.2

2675.9

2641.5

2616.4

2616.4
SPECIES

Au 11

Au 1

Au 1

Ald I

Au 1

Au 11

Au!
$12 \mu$

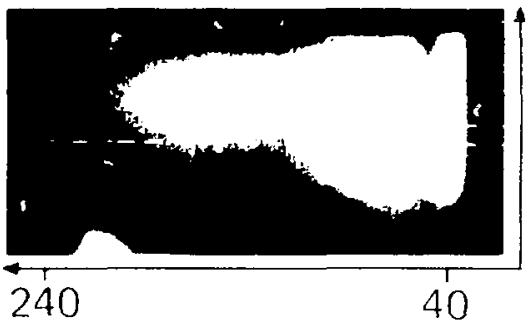

$50 \mu$

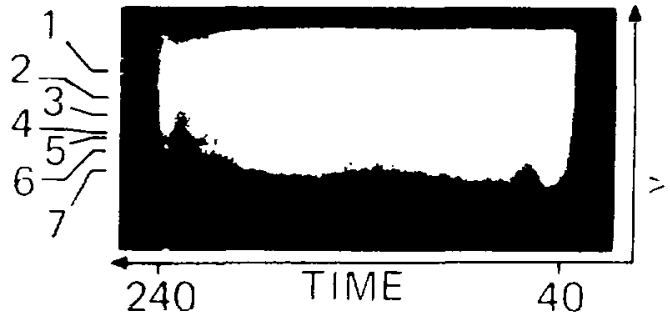

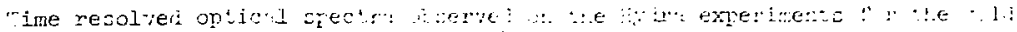

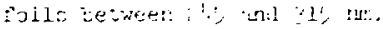


suggest a low density, low temperature plesma which 1s absorbing radiation from a hotter, denser plasma located behind it.

B. Theoretical Results

The diode code was used to simulate the deposition in $6 \mu$ wold with the Hydra dlode geometry for: (1) in the listt of negligible beam target Interaction; (2) with a simplified scattering and energy loss model; and (3) with and without space charge neutralization behind the foll (1.e., with and without Ion emission from the back side of the foll). The average speciflc power within a $1.0 \mathrm{~cm}$ diameter focal volume (1.e., roughly the FWhM of the radiation spacial profile) was $0.96 \mathrm{TW} / \mathrm{g}$ compared with $1 \mathrm{TW} / \mathrm{g}$ experimentally measured. The average number of passes through the foll was approximately 1.8 , comparing well with the experimentally measured values of 1.3 to 2 based on radiation temperature measurements and hard $x$-ray emission, respectively. The following qualitative facts were ubserved from the calculation: (1) scattering in the foll reduced the maximum current density on axis approximately 18 percent over the case of no beam foll interaction; (2) space charge neutralization lowered the average speciflc power by a factor of 2. Agreement with experiment was poor, however, In the shape of the radial deposition profile and for the case of a totally absorbing target.

In an attempt to understand the $x$-ray pinhole data for three planar Hydra anodes; $6 \mu \mathrm{m} \mathrm{Au}, 50 \mu \mathrm{m} \mathrm{Au}$, and $0.32 \mathrm{~cm}$ thick carbon, the CYLEM 25 Monte Carlo code was employed to study coupled electron/photon transport In the presence of certain assumed electromagnetic fields. The radial distribution of the source-electron current density was taken to be identical to the x-ray deposition proflle for thick carbon as shown in Fig. 7 . Th1s radial profile was chosen because of the small collisional albedo of 
carbon, and tacitly asaumes that transport of primary electrons from cathode to anode 18 not affected by the composition and thickness of that anode. When non-zero, the externally simulated self-magnetic field of the beam was obtained from this current density profile.

Fifteen calculations are summarlzed in Table 1. The three subgroups are distinguished by the angular distribution of the source current. A qualitative explanation for the measured $x$-ray profiles can be obtained from the 1sotroplc results shown in Fig. 13 where the radial profiles, normalized to their peak values of the forward bremsstrahlung emission are compared. The relatively sharply peaked profile for carbon is a consequence of the relatively small collisional albedos. The more broadly peaked profile observed in the case of the $50 \mu \mathrm{m}$ Au anode can be explained by the radial diffusion (1.e., surface migration ${ }^{7}$ ) of the large number of coll1sionally reflected electrons. The even broader profile observed for the $6 \mu \mathrm{m}$ Au anode, when the magnetic fleld is present on both sides, can be attributed to a more general radial diffusion resulting from the large number of re-entries. Thus, the trend of the results can be accounted for by calculations 1,2 , and 4, respectively. Note, however, that the absence of the magnetic field from the transmission side of the $6 \mu \mathrm{m}$ Au anode leads to a much more sharply peaked profile, because the large number of transmitted electrons escape (the mean number of re-entries, next to last column of Table 1 for calculations 4 and 5 differ by an order of magnitude). Thus, should the magnetic fleld not penetrate through the $6 \mu \mathrm{m}$ Au anode, some other mechanism (e.g., space charge reflexing ${ }^{4}$ ) would be necessary to account for the broad profile in Fig. 7 .

The normal incidence results are only of academic interest and are not relevant for superpinched beams. However, we have considered in 


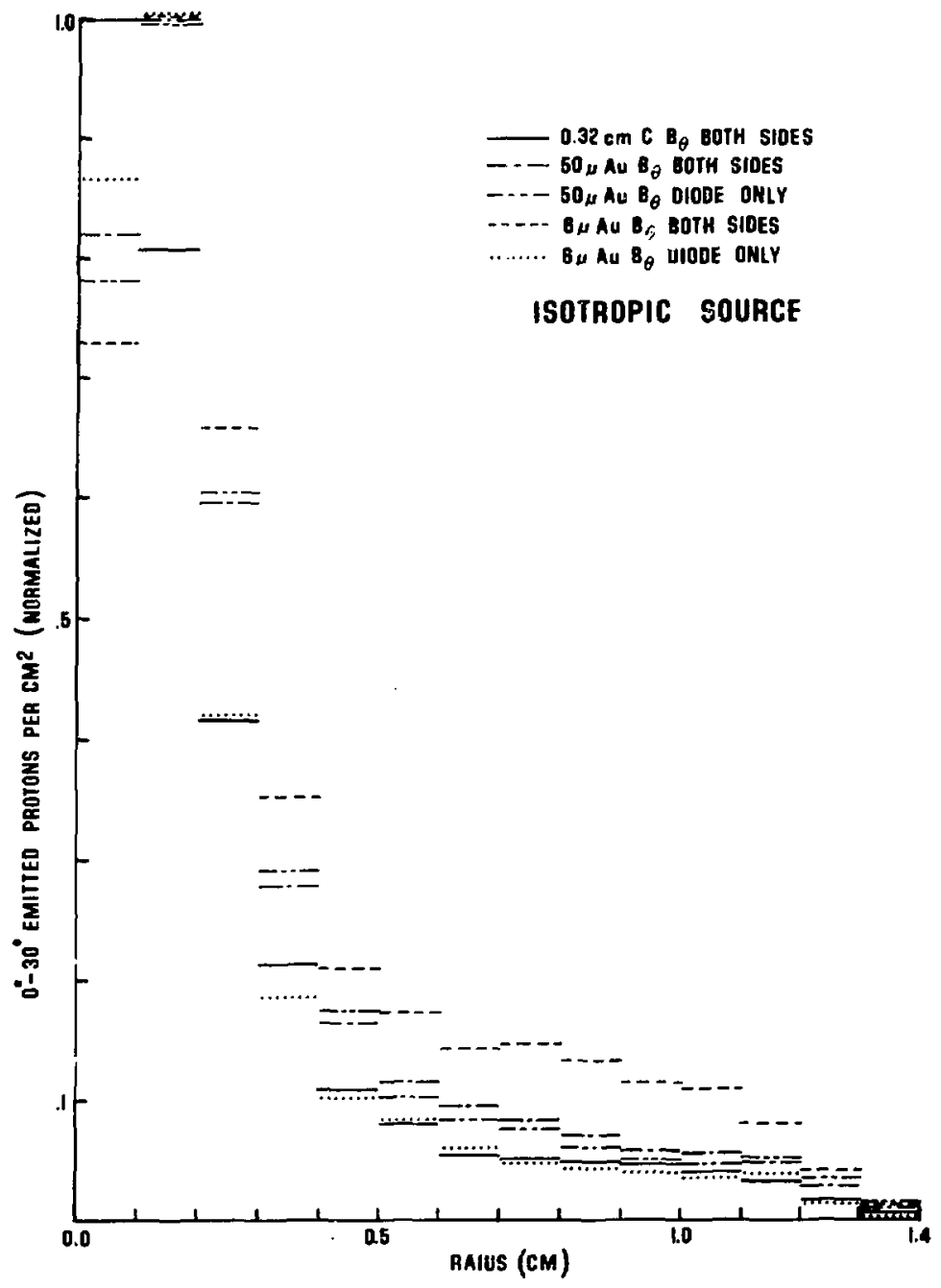

FIGURE 13

Theoretical predfetion of forwa bremsstrahlung as a function of anode escape radius for the $2_{\pi}$ 1sotropic source calculations listed in Table $I$, for conparison with $x-r a y$ pinhole measurenents on the Hydra experiments. 
calculation $6 \mathrm{vg}$. calculation 7, the effect of the presence of the magnetic field within the carbon anode. The maximum magnetic field $1 \mathrm{~s}$ about $65 \mathrm{~kg}$. This 18 not large enough for fleld effects to compete with callialonal effects within normal density $A u$, but it is large enough in the case of normal density carbon. 35 The peak in the radial power deposition profile (last column of Table I) Is more than a factor of two larger when the fleld exists within the carbon, and the mean number of re-entries is an order of magnitude greater. Since the peak depositions are averaged over a thickness of carbon that is greater than the range of the source electrons, the Increase In the true differential deposition when the field is pregent could be much greater than a factor of two. It 13 appropriate here to emphasize that none of these calculations account for the possibli1ty of additional enhancement of deposition resulting from anode expansion. 2,4 A cosine law angular distribution for the source current was used in the third group of calculations. This is probably more realistic than efther normal incidence or the isotropic distribution. Still, the basic trends in the results are the same. The peak power depositions in Trble II for calculations 12 and 13 indicate that the presence of the magnetic fleld within the carbon anode sustains the pinch against collisional scattering.

Comparison of peak powers in Table II with experimentally measured peak powers in Figs. 9 and 10 show very close agreement. In the case of the $6 \mu \mathrm{m} \mathrm{Au}$, the number of electron passes was estimated to 1.3 to 2 passes compared with over 3 passes theoretlcally. It appears that the case of a magnetic field on both sides of the foil, more closely correlates with the experimental data. 


\section{TABLE II}

Summary of model calculations. The second to last column is the average number of times that $a$ source electron re-enters (would be zero without macroscopic electromagnetic fields) the anode. The last column is the peak value of the radial specific power deposition profile $(0.1 \mathrm{~cm}$ resolution) for the given source current, averaged over the anode thickness; it always occurs in efther the central circular zone or the adjacent annular ring.

\begin{tabular}{|c|c|c|c|c|c|c|c|}
\hline $\begin{array}{l}\text { Source-Current } \\
\text { Angular } \\
\text { Distribution }\end{array}$ & Anod & & $\begin{array}{l}\text { Magnetic } \\
\text { Field }\end{array}$ & $\begin{array}{l}\text { Source } \\
\text { Current }\end{array}$ & $\begin{array}{r}\text { Mean No. of } \\
\text { Re-entries }\end{array}$ & $\begin{array}{c}\text { Peak } \\
\text { Deposition }\end{array}$ & $\mathrm{TW} / \mathrm{g}$ \\
\hline $\begin{array}{l}1 . \\
2 . \\
3 . \\
4 . \\
5 .\end{array}$ & $\begin{array}{r}.32 \\
50 \\
50 \\
6 \\
6\end{array}$ & $\begin{array}{l}\mathrm{Cm} \mathrm{C} \\
\mathrm{Au} \\
\mathrm{Au} \\
\mathrm{Au} \\
\mathrm{Au}\end{array}$ & $\begin{array}{l}\text { both sides } \\
\text { both sides } \\
\text { diode only } \\
\text { both sides } \\
\text { diode only }\end{array}$ & $\begin{array}{l}I_{0} \\
I_{0} \\
I_{0} \\
I_{0} \\
I_{0}\end{array}$ & $\begin{array}{l}0.386 \\
2.402 \\
1.332 \\
3.744 \\
0.363\end{array}$ & $\begin{array}{l}0.7619 \\
2.2508 \\
1.564 \\
2.460 \\
1.303\end{array}$ & $\begin{array}{l}6 \% \\
3 \% \\
5 \% \\
4 \% \\
7 \%\end{array}$ \\
\hline $\begin{array}{l}6 . \\
7 . \\
8 . \\
9 . \\
11 .\end{array}$ & $\begin{array}{r}.32 \\
.32 \\
50 \\
50 \\
6 \\
6\end{array}$ & $\begin{array}{l}\mathrm{Cm} C \\
\mathrm{Cm} C \\
\mathrm{Au} \\
\mathrm{Au} \\
\mathrm{Au} \\
\mathrm{Au}\end{array}$ & $\begin{array}{l}\text { everywhere } \\
\text { both sides } \\
\text { both sides } \\
\text { diode only } \\
\text { both sides } \\
\text { diode only }\end{array}$ & $\begin{array}{l}I_{0} \\
I_{0}^{0} \\
I_{0}^{0} \\
I_{0}^{0} \\
I_{0}^{0}\end{array}$ & $\begin{array}{l}0.223 \\
0.023 \\
1.985 \\
0.967 \\
4.259 \\
0.029\end{array}$ & $\begin{array}{l}2.240 \\
0.9207 \\
2.2 .3 \\
1.722 \\
2.184 \\
0.5358\end{array}$ & $\begin{array}{l}5 \% \\
4 \% \\
5 \% \\
6 \% \\
8 \% \\
10 \%\end{array}$ \\
\hline $\begin{array}{l}12 . \\
13 . \\
14 . \\
15 .\end{array}$ & $\begin{array}{r}.32 \\
.32 \\
50 \\
6\end{array}$ & $\begin{array}{l}\mathrm{Cm} \mathrm{C} \\
\mathrm{Cm} \mathrm{C} \\
\mathrm{Au} \\
\mathrm{Au}\end{array}$ & $\begin{array}{l}\text { everywhere } \\
\text { both sides } \\
\text { both sides } \\
\text { both sides }\end{array}$ & $\begin{array}{l}0.74 \mathrm{I}_{\mathrm{o}} \\
0.74 \mathrm{I}_{\mathrm{o}} \\
0.74 \mathrm{I}_{\mathrm{O}} \\
0.74 \mathrm{I}_{\mathrm{o}}\end{array}$ & $\begin{array}{l}0.295 \\
0.179 \\
2.007 \\
2.286\end{array}$ & $\begin{array}{l}1.015 \\
0.6059 \\
1.433 \\
1.363\end{array}$ & $\begin{array}{l}4 \% \\
5 \% \\
4 \% \\
10 \%\end{array}$ \\
\hline
\end{tabular}


PROTO I

\section{A. Experimental Results}

F1gure 14 shows the apparent 1ncident current density based on $x$-ray pinhole photographs assuming a single pass through 50, 12.7 and $6.4 \mu \mathrm{m}$ thick gold folls on the Proto I experiments. The total current in the plnch was normalized to absolutely callbrated photographic film, Type M x-ray film. The radius of the foll was $0.5 \mathrm{~cm}$. Peak apparent current densities for $50,12.7$ and $6.4 \mu \mathrm{m}$ thick gold folls were $2.5,1.8$, and $1.2 \mathrm{MA} / \mathrm{cm}^{2}$, respectively. We see again that the apparent current density 1s lowered for thinner folls. For these partfcular shots, approximately 60 , SO, and 50 percent, respectively, of the total diode current was found in the pinch region. Relative PIN diode measurements behind the photographic film on the Image plane of the pinhole camera system verifled the $x$-ray flux profile. The pinhole camera viewed the forward golng bremsetrahlung and was very insensitive to bremsstrahlung from electrons coming from the side of the foll away from the diode.

Figura 15 shows the apparent incident current density for aluminum folls of 206, 89, 38 and $6.4 \mu \mathrm{m}$ thickness on the Proto-I accelerator. The pinhole camera assembly was mounted behind the cathode and was therefore most sensitive to backward going brensstrahlung. However, if electrons re-enter the foll from the back side, then the pinhole camera system would be most aensitive to the brensstrahlung coming from these electrons. To account for the fluence of $x$-rays from these aluminum shots, the electrons must have made a second pass through the snode fo11, entering the foll from the back alde. Based on the $x$-ray fluence, the apparent incident peak current densities for the above th1ckness folls were $2.0,1.7,1.7$, and $1.3 \mathrm{MA} / \mathrm{cm}^{2}$. These folls had a $1 \mathrm{~cm}$ radfus. The percentage of current 


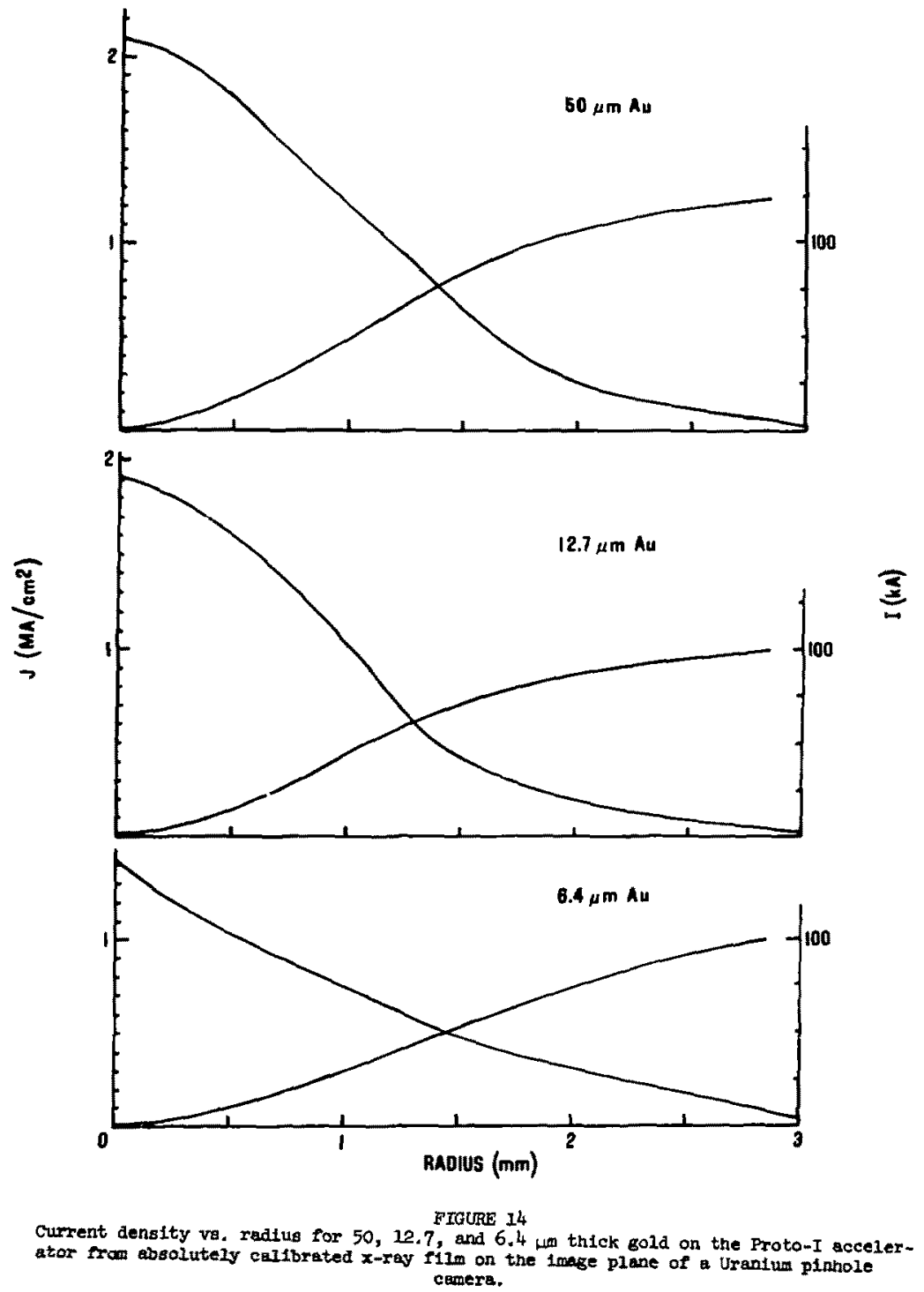



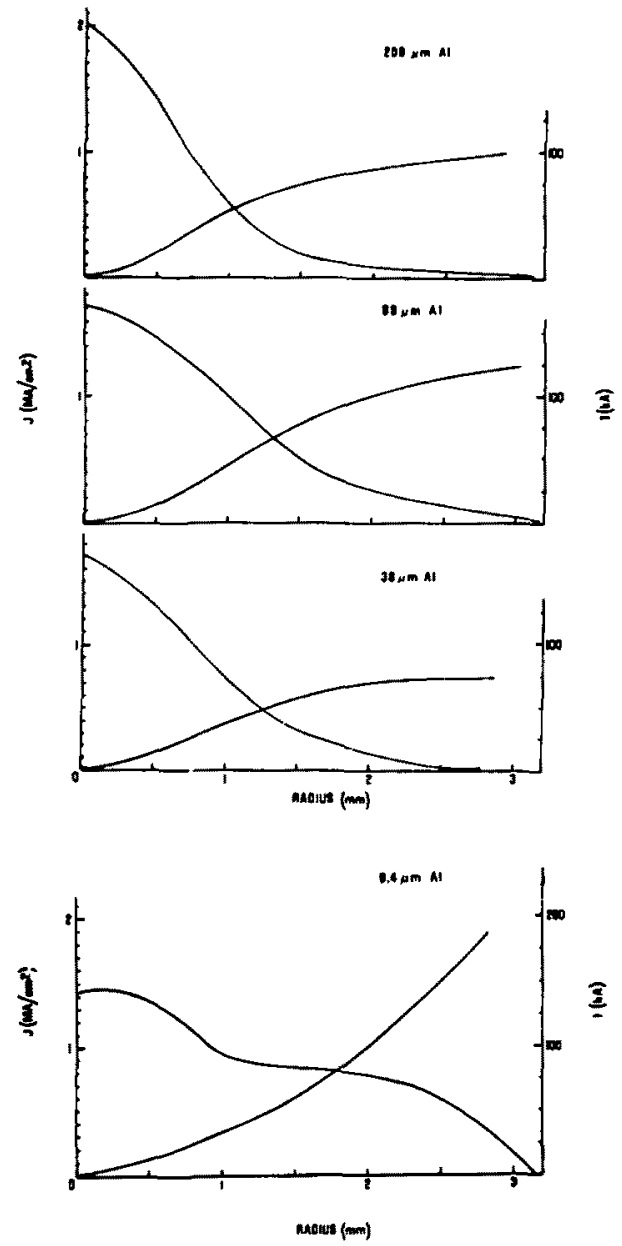

FIGURE 15

Current density and total current vs, radius for $6.4 \mathrm{um}$ thick aluminum on the Proto-I accelerator. 
In the pinch region out of the total electron current avallale were 50,63 , 100 , and 100 percent, respectively, for the obove thicknesses.

F1gure 16 shows the apparent incident current density for $6.4 \mu$ m thick aluminum with a $0.5 \mathrm{~cm}$ radius. Based on absolute calibration of $x$-ray film located on the Image plane of a pinhole camera, the apparent peak current density was $3.8 \mathrm{MA} / \mathrm{cm}^{2}$. In this case, the pinhole camera system was primarlly sensitive to forward golng bremstrahlung from the anode. Based on the $x$-ray fluence, 100 percent of the total dlode current was incident on the pinch region. Only a single pass of an electron was required for this x-ray fluence,

F1gure 17 shows the temporal history of the radiation temperature measurements for $25,12.7$ and $6.4 \mu \mathrm{m}$ thick gold folls on the Proto-I experiments based on unfiltered XRD measurements. The source area was chosen from the hard $x$-ray measurements as discussed before. The average deposition per electron with a local macroscopic electric field in the diode, and including the electron spectra for the respective shots were $3.8,3.5$, and $2.7 \mathrm{MeV}-\mathrm{cm}^{2} / \mathrm{g}$. The temperatures were compared with calculations from the code CHART $\mathrm{D}^{14}$ as previously described. The closest fit to the experimental measured temperatures were peak speciflc powers of $6.8,6.4$, and $2.7 \mathrm{TW} / \mathrm{g}$, respectively. These peak spectfic powers correspond to peak current densities of $1.8,1.8$, and $1.0 \mathrm{MA} / \mathrm{cm}^{2}$, respectively. These peak current densities are consistent with the $x$-ray fluence measurements, assuming only a single pass of the electrons through the gold folls. Figure 18 ghows the temporal history of the unfiltered XRD radiation temperature measurements for 38 and $6.4 \mu \mathrm{m}$ thick aluminum folls on the Proto I experiments. The average deposition per electron for a single passthrough the foll with a local macroscopic electric fleld in the diode, and 


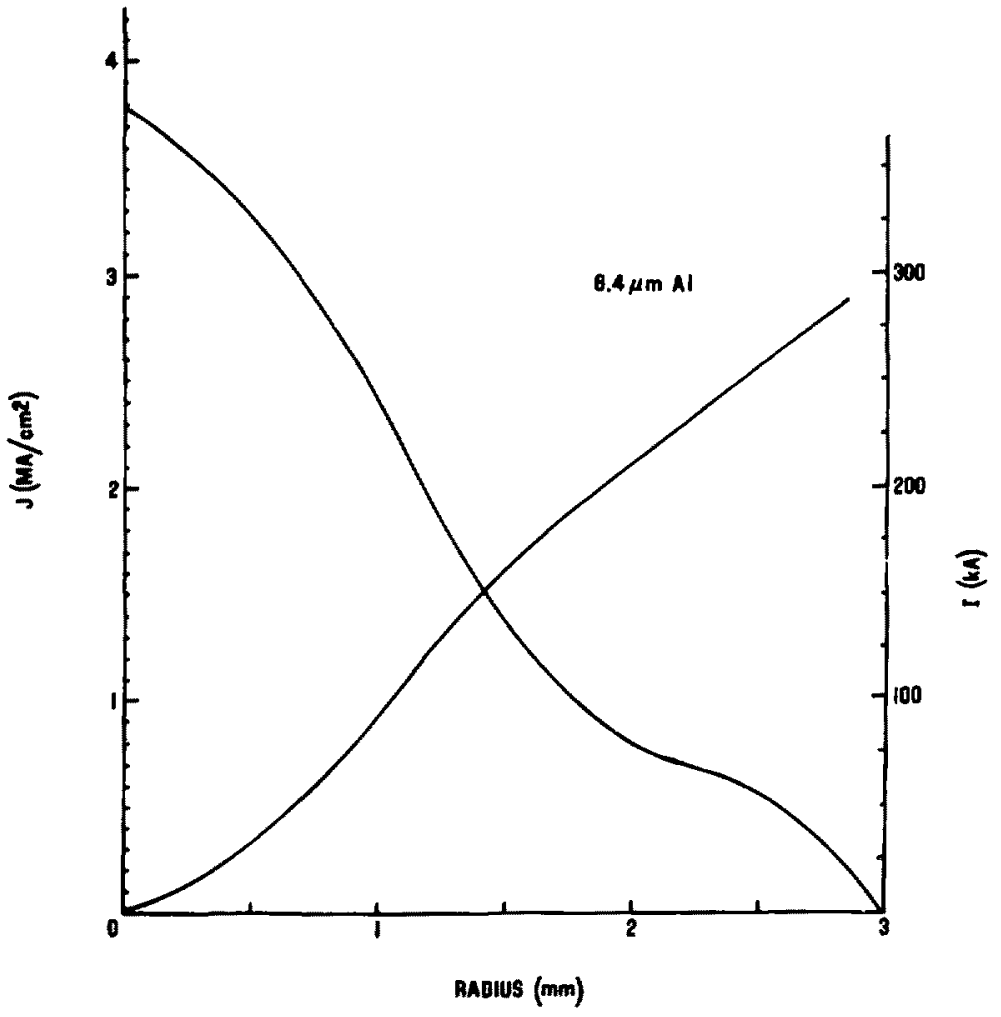

FIGURE 16

Current density and total current va. radius for 6.4 um thick aluminum with $0.5 \mathrm{~cm}$ radius. 

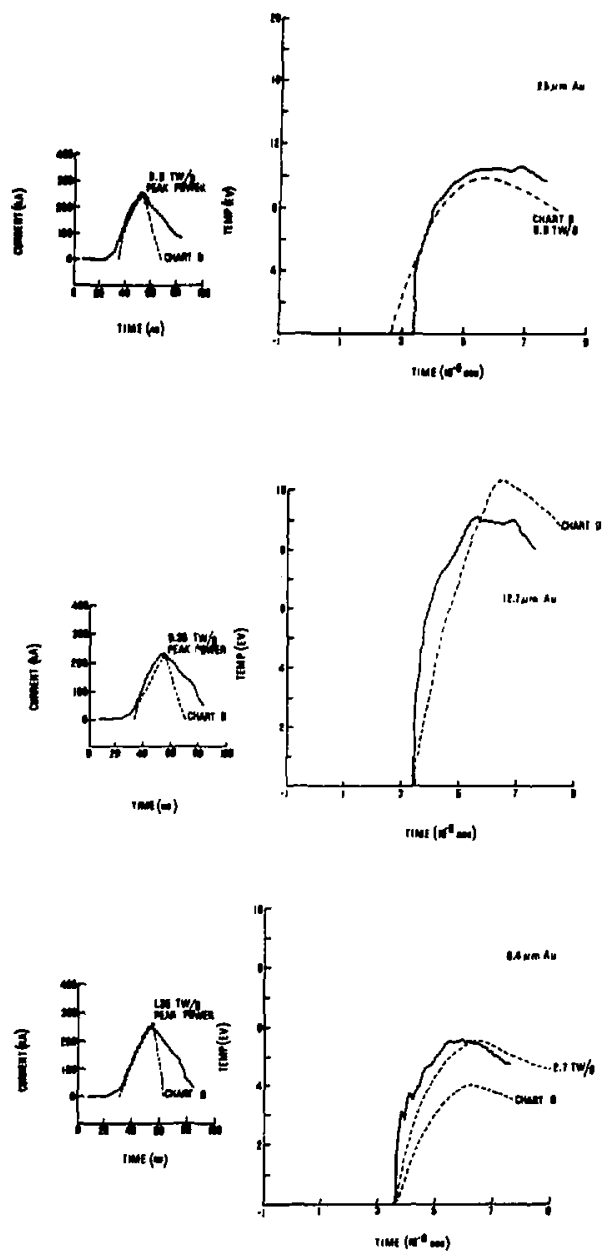

FIGURE 17

Temporal history of the radiation temperature mesenrements on the Proto-I experiments

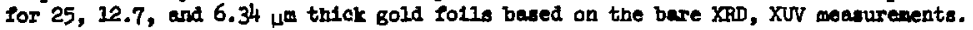



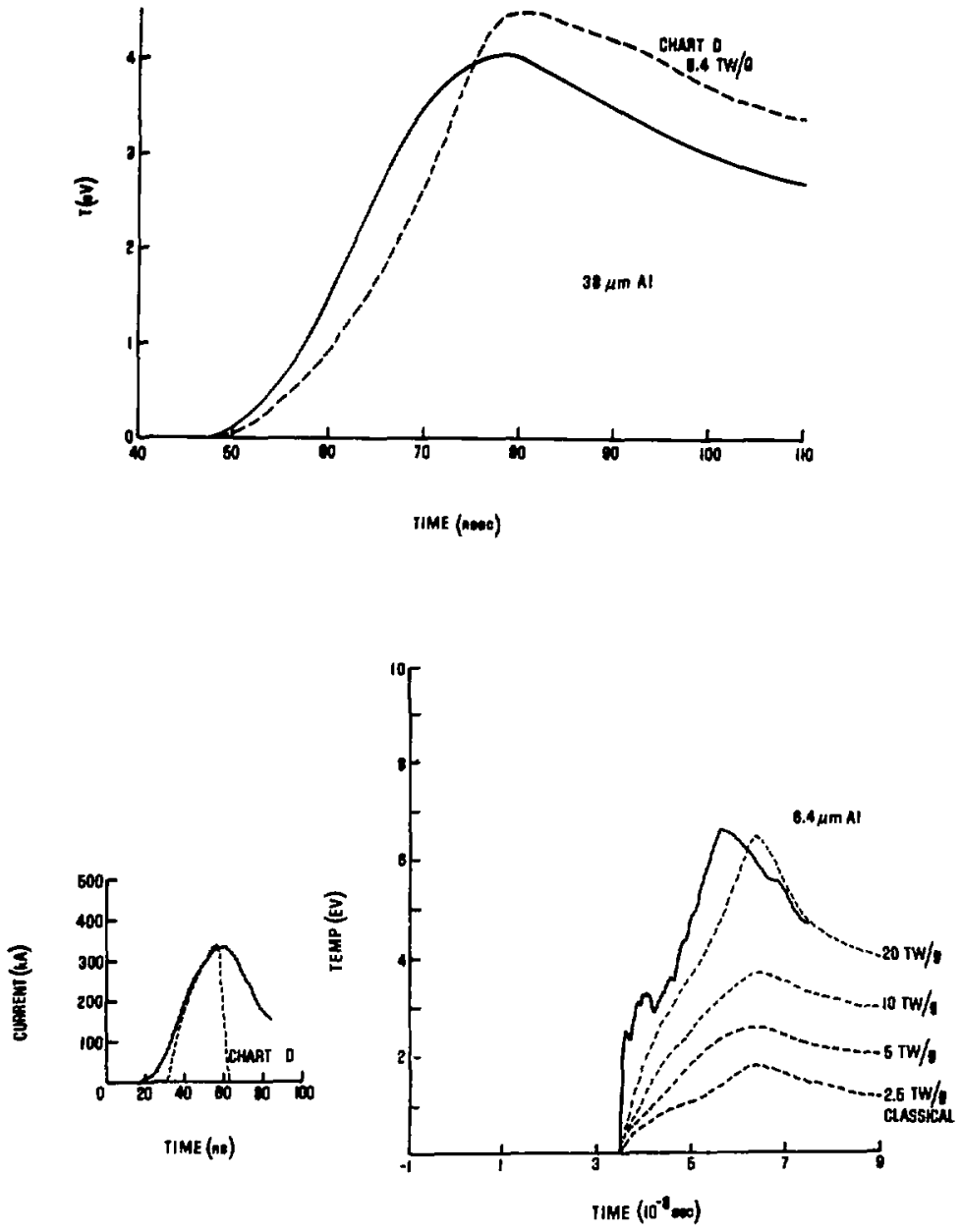

FIGURE 18

Teuporel bistory of the radiation temperature measurements on the Proto-I experiments for 38 and 6.4 w thick aluminum based on bare XRD, XVV measurements. 
Including the electron opectra for the respective shots, were 3.0 and $3.7 \mathrm{MeV}-\mathrm{ca}^{2} / \mathrm{g}$. The experimentally measured temperatures from the unflltered XRDs were compared with temperatures calculated from t ie code CHART D. 14 The closest fit to the experimentally measured temperatures were peak specific powers of 9.4 and $20 \mathrm{TW} / \mathrm{g}$. Th1s would correspond to apparent peak current densities on a single electron pass of 3.1 and $5.3 \mathrm{MA} / \mathrm{cm}^{2}$. However, from quantitetive $x$-ray fluence measurements (see Figs. 16 and 17), for two passes through the aluminum folls, the apparent peak current denstt1es, were 1.7 and $3.8 \mathrm{MA} / \mathrm{cm}^{2}$. These measured peak current densitfes Imply effective depositions of 5.5 and $5.2 \mathrm{MeV}-\mathrm{cm}^{2} / 8$ as opposed to 3.0 and $3.7 \mathrm{MeV}-\mathrm{cm}^{2} / \mathrm{g}$ for 38 and $6.4 \mu \mathrm{m}$ thick aluminum fof 1.8 for a single electron pass, respectively. Equivalently, an average electron deposits 4.9 and 1.7 percent of 1 tg energy as compared with 2.7 and 1.2 percent of 1 ts energy with a single pass through the above respective foils.

B. Theoretical Resulcs The diode code was used to simulate the deposition in $6 \mu \mathrm{m}$ goli and $6 \mu \mathrm{m}$ aluminum folls with the Proto-I diode geometry: (1) In the limit of negligible beam target interaction; (2) with a simplified scattering and energy loss model; (3) varying the lon specles of the lon component of total current, and (4) with and without space charge neutralization behind the foll. The average speciflc power within a $0.16 \mathrm{~cm}$ radius local volume (1.e., roughly the FWHM of the radiation spacial profile) was $4.7 \mathrm{TW} / \mathrm{gm}$ for $6 \mu \mathrm{m}$ gold and $9.0 \mathrm{TW} / \mathrm{gm}$ for $6 \mu \mathrm{m}$ aluminum for the data shown In F1g. 14 and data simllar to that in F1g. 16, except with a peak specific power of $10 \mathrm{TW} / \mathrm{g} \cdot{ }^{36}$ The experimentally measured peak specific power for the $6 \mathrm{\mu n}$ gold shot was $2.7 \mathrm{TW} / \mathrm{g}$ (see F1g. 17). However, whereas a 100 percent of the current was incident in the case of the $6 \mu$ aluminum 
target (see FIg. 16), only 50 percent was incident on the $6 \mu \mathrm{m}$ gold target, the rest being lost at large radi1. Experimentally, we find that a single electron pass is sufficient to account for the deposition in the gold folls on the Proto I acceleratar, whereas the diode calculation predicts an Incident current of 100 percent and a deposition consistent with 3.2 passes by a given electron. However, if the current were reduced theoretically, the deposition leve1s would be roughly consistent. In the case of the $6 \mu \mathrm{m}$ aluminum, the 9 to $10 \mathrm{TW} / \mathrm{gm}$ is consistent with an average of 1.3 passes for a cosinusoldal angular distribution of electrons compared with 2.9 passes with the diode calculation. The discrepancy could be caused by an electron angular distribution that is more nearly normal, with the deposition requiring a larger number of experfmental electron passes. In the case of the $6 \mu \mathrm{m}$ gold calculation, the scattering model may be too simple as manifested by a predicted spatial deposition profile that is much too narrow and the lack of time dependence.

Coupled electron-photon Monte Carlo calculations were performed to look at the effect of scattering on the deposition in planar $6 \mu \mathrm{m}, 12 \mu \mathrm{m}$ and $50 \mu \mathrm{m}$ gold targerts on the Proto I accelerator. Both one-d1mensional (TIGER) and two-dimenstonal (CYLEM) calculations were performed. For all calculations, a cosinusoidal angular distribution for the incident electrons and a radial distribution consistent with the diode calculations were assumed for each bin of the diode simulation in order to smooth the discontinuties in the profile. The two-dimensional calculations included magnetic flelds consiatent with the current profile and electric fields which were roughly equal to the self-consistent fields calculated in the diodee simulations. Variation in the electric fleld in the diode by factors of 2-3 in the CYLEM calculation resulted in negligible changes 
( 10 percent) In the energy deposited in a radius of $\$ 0.75 \mathrm{~mm}$. However, diode calculations with ion emission coning from the back of $6 \mu$ m thick gold and aluminum folls resulting in space charge neutralization behind the foll, predicted energy deposition that was a factor of two lower than that obtalned for the case of no Ion emission from the back side of tre fo11.

The two-dimensional calculations, with 51 percent of the incident electrons striking the target region, Indicate that 0.8 percent, 2.2 percent and 10.4 percent of the incident energy will be deposited for 6,12 , and $50 \mu$ m thick gold folls, respectively. One dimenstonal calculations were performed with the Monte Carlo code TIGER for the case of $6 \mu \mathrm{m}$ and $50 \mu \mathrm{m}$ gold targets and compared with two-dimenstonal calculations in which the flelds at the rear of the anode were space charge neutralized. The TIGER calculations were performea bot! by allowing all transutted and reflected particles to escape and by allowing specular reflection of the reflected particles at the front surface of the target. The arithmetic mean of the two-calculations predicted 0.8 and 9.2 percent compared with 0.8 and 9.7 percent for the two-dimensional calculations.

The good agreement between the 1 and 2 -dimenstonal codes $1 \mathrm{n}$ the case where half the back-scattered electrons are reintroduced indicate a relatively small enhancement due to recirculation in the diode field; about 80 percent of the dose is obcalned if no recirculation occurs, The lack of recirculation is apparently a result of the relatively low value of bean $\nu / \gamma$, namely, of order 1 . The observed lack of reflexing in the submillimeter radius pinch region does not imply that no reflexing octurs, but only that the reflexing electrons tend to strike the anode at radif larger than the pinch region. This to consistent with experiment, whereby 
no rec1rculation of electrons in gold folls was necevary to account for the energy depostition (see F1g. 18).

\section{CONCLUSION}

The 1mportant point to otress from this work is that electromagnetic effects assoclated with self-electric and magnetic flelds, as well as wecroscoplc fields in the diode, strongly interact with fulls of thicknesses less than 50 microns. A great many assumptions went into the analysis, both theoretically and experimentally. The qualicative agreement between both seems remarkable. Experimentally, an lsotroplc angular distribution of electrons averaged over the focal volume was assumed. The good agreement on spectflc depositions as obtalned from the hard $x$-ray flux and radiation temperature measurements testify to 1 ts validity. Secon 1, a blackbody photon spectrum was assumed and justified by the good agreement between optical and XUV measurements, as well by the lack of IIne emission during the power pulse. Theoretically, the diode calculations assumed a time Independent electron spectrum, as well as no interaction with the folls. This was justifled by the good agreement with exporiment for the average specific deposition in the focal volume. The Monte Carlo calculations assumed an incldent electron spatial profile given by either $x$-ray pinhole profiles, from a low-z (1.e., carbon) target or by the diode calculation, and Ignored hydrodynamic motion of the folls. The good agreement with the peak specific depositions for the radiation temperatures testifles to 1 ts val1d1ty.

We have shown that, on the average, an electron makes more than a single pass in a $6 \mathrm{~km}$ thick gold foll for a $\nu / \gamma=2.5$ electron beam ( $800 \mathrm{kV}$, $100 \mathrm{kA}$ ) within a focal radius of $0.5 \mathrm{~cm}$. This was manifested by enhanced brewetrahlung and by spectfic power deduced from radiation temperature 
measurenents that could not have been accounted for by a angle electron pass. On the basis of the Monte Carlo calculations, a $6 \mu \mathrm{m}$ gold foll with a magnetic field on the both sides of the foll could account for the deposition. It was not necessary to appeal to electrostatic reflexing to account for the deposition.

In the case 38 and $6 \mu$ m thick aluminum folls, more than a single electron pass was necessary to account for the deposition. In the case of the $6 \mu$ m aluminum foll, enhanced deposition was observed for a $\nu / \gamma \sim 2.2$, but not for $\nu / \gamma \sim 1.1$ suggesting agreement with magnetic stopping and space-charge neutralization behind the foll. The $38 \mathrm{~m}$ aluminum data suggest.8 possible electrostatic reflexing, since $\nu / \gamma$ of the incident ieam was about 1.1. No enhancement was observed for the gold folls, for an Incident beam with a $\nu / \gamma$ of about 1.1 .

At present, although enhancements of a factor of 2 hase been observed, only a small amount of the incident electron's energy ( 1 - 10 percent) has been deposited in the foll. A much greater fraction of the electron's energy must be deposited before thin foils may be utilized in electron beam fusion targets. Th1s w1ll require efther substantially higher current densitles than achleved in these experiments or externally applied magnetic f1elds,* 


\section{REFERENCES}

1. G. Yonas, J. H. Poukey, k. R. Prestwich, J. R. Freaman, A. J. Toepfer, and M. J. Clauser, Nucl. Fusion 14, 731 (1974).

2. P. Gilad and Z, Z1namon, Phys. Rev. Lett, 37, 697 (1976). P. Gilad, S. Miller, and 2. Z1namon, App1. Phys. Lett. 31, 151 (1977). P. Gilad, Z. Kaplan, S. Miller, E. Nard1, E. Peleg and Z. Zinamon, preprint, (to be published).

3. M. J. Clauser, L. P. M1x, J. W. Poukey, J. P. Quintenz, and A. J. Toepfer, Phys. Rev. lett. 38, 398 (1977).

4. M. M. Widner, J. W. Poukey, and J. A. Halilelb, Sr., Phys. Rev. Lett. $38,548(1977)$.

5. S. L. Bogolyubsk11, B. P. Gerasimov, V. I. Liksonov, Yu. p. Popov, L. I. Rudakov, A. A. Samarsk11, V. P. Smirnov, and L. I. Urutskoev, JETP Lett. 24, 178 (1976). M. V. Babikin, K. A. Bafgarin, A. V. Bartov, S. L. Borgolyubsky, U. V. Vastlevsky, V. I. Liksonov, V. 1. Migiritsky, L. I. Rudakov, V. P. Smirnov, preprint, (to be published).

6. F. Winterberg, Nucl. Fusion 12, 353 (1972).

7. J. A. Halble1b, Sr, and W. H, Vandevender, IEEE Trans. Nuc1. Sc1. NS-22, 2356 (1975). J. A. HaIble1b, Sr., J. Appl. Phys. 45, 4103 (1974).

8. S. Humphries, Jr., R. N. Sudan, and W. C. Cond1t, Jr., Appl. Phys. Lett. 26,667 (1975).

9. D. S. Prono, J. M. Creedon, I. Smith, and N. Bergstrom, J, Appl. Phys. 46,3310 (1975).

10. S. A. Goldstein and J. Gulllory, Phys, Rev. Lett. 3.5, 1160 (1975).

11. D. A. Tidman, Phys, Rev. Lett. 35, 1228 (1975).

12. S. Naka1, K. Imasak1 and C. Yamanaka, Nucl. Fusion Suppl. I, p. 207 (1977). K. Imasak1, S. Miyamoto, S. Naka1 and C. Yamanaka, preprint, (to be published).

13. D. J. Johnson, W. F. Oliphant, G. A. Doschek, and U. Feldman, J. App 1. Phys . 49, 113 (1978).

14. S. L. Thompson, Sand1a Laboratory Report No. SC-RR-71-0713, 1972 (unpubl1shed).

15. J. W. Poukey, J. R. Freeman, G. Yonas 10, 954 (1973).

16. J. H. Poukey, J. Vac. Sc1. Techno1. 12, 1214 (1975).

17. S. A. Goldsteln and R. Lee, Phys. Rev. Lett. 35, 1079 (1975). 
18. J. P. Quintenz and J. W. Youkey, J. Appl. Phys. 48, 2287 (1977).

19. G. Yonas, K. R. Prestwich, J. W. Poukey, and J. R. Freeman, Phys. Rev. Lett. 30, 164 (1973).

20. M. M. Widner, E. J. T. Burns, M. J. Clauser, S. A. Coldstein,

J. A. Halble1b, Sr., L. P. Mix, J. N. Olsen, F. C. Perry, J.W. Poukey, J. P. Quintenz, and A. J. Toepfer, in Proceedings of the 2 nd Inter. Toplcal Conference on High Power Electron and Ion Beam Research and Technology, Vol. 1, 287 (1977).

21. B. Ross1, X. Greisen, Rev. Mod. Phys. 13, (1941) 240 ,

22. M. J. Berger and 5. M. Seltzer, Natlonal Bureau of Standards Reports Nos. 9836 and 9837,1968 (unpubl1shed).

23. J. H. Halble1b, Sr. and W. H. Vandevender, Nucl. Sc1. Eng. 57, 94 (1975).

24. J. A. Halble1b, Sr, and W. H. Vandevender, Nuc1. Sc1. Eng, 61, 288 (1976).

25. J. A. Kalblelb, Sr., and W. H. Vandevender, J. Appl. Phys. 48, 2312 (1977).

26. J. A, Halblelb, Sr,, and M, M. W1dner, IEEE Trans, Nucl, Soc. NS-24, 2490 (1977). J. A. Halble1b, Sr., M. M. Widner, J. W. Poukey, and J. P. Quintenz, Bu11. Amer. Phys. Soc. 22, 1061 (1977).

27. P. A. Miller, private communication.

28. D. J. Johnson and Shyke A. Goldstefn, J. App1. Phys. 48, 2280 (1977).

29. J. M. Crredon, 3. App1. Phys. 46, 2946 (1975).

30. Shyke A. Goldstein and R, Lee, Phys. Rev. Lett. 35, 1079 (1975).

31. J. W. Poukey, in Proceedings of the International Toplcal Conference on Electron-Beam Research and Technology, Albuquerque, NM 1975, edited by $G$. Yonas (U. S. Department of Commerce, Washington, D.C., 1976), Vol. I, p. 247.

32. R. D. Evans, The Atom1c Nucleus, McGraw-H111 Book Co., 1955, p. 723 and references therein.

33. J. R. Kerns and D. J. Johnson, J. Appl. Phys. 45, 5225 (1974).

34. Kindly provided by M. J. Clauser and A. V. Farnsworth, Sandia Laboratories.

35. J. A. Ha1ble1b, Sr., IEEE Trans, Nuc1. Sc1, NS-21, 221 (1974).

36. E. J. T. Burns, S. A. Goldstein, J. N. O1sen, and L. P. Mix, Bull. Amer. Phys., Soc. 22, 1084 (1977).

37. M. M. Wfdner, Steven A. Goldste1n, C. W. Mendel, E.J.T. Burns, J. P. Quintenz, and A. V. Farnoworth, Jr., submitted for publication. 
DISTRIBUTION

TID-4500-R66 UC-21 (208)

Commissareat a'l Energle Atomique Centre A'Etudes de Lime1l

BP No. 27

94190 v1lleneuve, St. Georges, FRANCE

Attn: C. Patou

M. Delobeau

Department of Energy

Division of Laser Fusion

Washington, D.C, 20545

Attn: $T$. Godlove

S. Kohales

Physics International Co. 2700 Merced Street San Leandro, Callfornia

Attn: R. Genar1o

S. Putnam

C. Stallings

G. Delbacha

E. Goldman

AFOSR/NT

Bolling Atr Force Base

Washington, D.C. 20332

Attn: Capt. R. Gullickson

Maxwe11 Laboratortes, Inc.

9244 Balboa Avenue

San Diego, California 92123

Attn: P. Korn

A. Krebs

A. Kolb

Naval Research Laboratory

Code 7720

Washlngton, D.C. 20375

Attn: G. Cooperstein

D. Mosher

P. Turch1

D. Nagel

T. Coffey

Universtey of California

Department of Phystco

Irvine, Cal1fornla 92664

Attn: $N$. Rostoker

C. Roberson
Massachusetts Institute of Technology 77 Massochusetts Avenue

Room 36-213

Cambr1dge, Magsachussetts 02139

Attn: G. Bekef1

Columbia University

School of Englneering \& Applied Sclenc.

Plasma Laboratory

New York, New York 10027

Attn: R. A. Gross

Cornell University

Labotatory of Plasma Studies

308 Upson

Ithaca, New York 14850

Attn: D. Hammer

R. N. Sudan

H. Flelschmann

J. Nation

Z. Zinamon

Lawrence Livermore Laboratory

P.0. Box 808, L-545

Livermore, California 94550

Attn: D. Meeker

T. Emmett

$T$. Nuchols

D. Henderson

R. Perkins

Afr Force Weapons Laboratory

K1rtland A1r Force Base

New Mexico 87117

Attn: W. L. Baker

No. Carolina State Univ. at Raleigh

School of Physical and Math. Sclence

P.0. Box 5342

Raleigh, NC 27650

Attn: J. J. K1⿴囗十

KMS Fusion, Inc.

394 Research Park Dr.

P.O. Box 1567

Ann Harbor, Michigan 48106

Attn: H. Gomberg

UnIverstey of Rochester

Laser Energetics Laboratory

Rochester, NY 14627

Attn: $M$. Lubin 